\title{
An analysis of the temperature dependence of force, during steady shortening at different velocities, in (mammalian) fast muscle fibres
}

\author{
H. Roots $\cdot$ K. W. Ranatunga
}

Received: 3 April 2008/Accepted: 7 May 2008/Published online: 4 June 2008

(C) The Author(s) 2008

\begin{abstract}
We examined, over a wide range of temperatures $\left(10-35^{\circ} \mathrm{C}\right)$, the isometric tension and tension during ramp shortening at different velocities $\left(0.2-4 L_{0} / \mathrm{s}\right)$ in tetanized intact fibre bundles from a rat fast (flexor hallucis brevis) muscle; fibre length $\left(L_{0}\right)$ was $2.2 \mathrm{~mm}$ and sarcomere length $\sim 2.5 \mu \mathrm{m}$. During a ramp shortening, the tension change showed an initial inflection of small amplitude $\left(P_{1}\right)$, followed by a larger exponential decline towards an approximate steady level; the tension continued to decline slowly afterwards and the approximate steady tension at a given velocity was estimated as the tension $\left(P_{2}\right)$ at the point of intersection between two linear slopes, as previously described (Roots et al. 2007). At a given temperature, the tension $P_{2}$ declined to a lower level and at a faster rate (from an exponential curve fit) as the shortening velocity was increased; the temperature sensitivity of the rate of tension decline during ramp shortening at different velocities was low $\left(Q_{10} 0.9-1.5\right)$. The isometric tension and the $P_{2}$ tension at a given shortening velocity increased with warming so that the relation between tension and (reciprocal) temperature was sigmoidal in both. In isometric muscle, the temperature $T_{0.5}$ for half-maximal tension was $\sim 10^{\circ} \mathrm{C}$, activation enthalpy change $(\Delta H)$ was $\sim 100 \mathrm{~kJ} \mathrm{~mol}^{-1}$ and entropy change $(\Delta S) \sim 350 \mathrm{~J} \mathrm{~mol}^{-1} \mathrm{~K}^{-1}$. In shortening, these were increased with increase of velocity so that at a shortening velocity $\left(\sim 4 L_{0} / \mathrm{s}\right)$ producing maximal power at $35^{\circ} \mathrm{C}, T_{0.5}$ was $\sim 28^{\circ} \mathrm{C}, \Delta H$ was $\sim 200 \mathrm{~kJ} \mathrm{~mol}^{-1}$ and $\Delta S \sim 700 \mathrm{~J} \mathrm{~mol}^{-1} \mathrm{~K}^{-1}$; the same trends were seen in the tension data from isotonic release experiments on intact
\end{abstract}

H. Roots $\cdot$ K. W. Ranatunga ( $\square)$

Muscle Contraction Group, Department of Physiology

\& Pharmacology, School of Medical Sciences,

University of Bristol, Bristol BS8 1TD, UK

e-mail: k.w.ranatunga@bristol.ac.uk muscle and in ramp shortening experiments on maximally Ca-activated skinned fibres. In general, our findings show that the sigmoidal relation between force and temperature can be extended from isometric to shortening muscle; the implications of the findings are discussed in relation to the crossbridge cycle. The data indicate that the endothermic, entropy driven process that underlies crossbridge force generation in isometric muscle (Zhao and Kawai 1994; Davis, 1998) is even more pronounced in shortening muscle, i.e. when doing external work.

Keywords Temperature effects · Force-velocity relation . Force generation · Enthalpy $\cdot$ Entropy $\cdot$ Thermodynamics

\section{Introduction}

The maximal isometric force of mammalian muscle increases in warming from low temperatures to physiological temperatures $\left(>30^{\circ} \mathrm{C}\right.$; Hadju 1951 ; Ranatunga and Wylie 1983); the subsequent, more detailed, studies showed that the force versus reciprocal absolute temperature is sigmoidal with a half- maximal force occurring at 8$10^{\circ} \mathrm{C}$ (Ranatunga 1994, 1996; Coupland and Ranatunga 2003). Studies that used rapid temperature-jump ( $T$-jump) and other techniques also showed that the muscle force generation is endothermic (Davis and Harrington 1987; Goldman et al. 1987; Bershitsky and Tsaturyan 1992; Zhao and Kawai 1994; Ranatunga 1996) so that the rate of force rise to a small $T$-jump increased with temperature $\left(Q_{10} \sim 3-4\right)$. It may be argued that, if active isometric muscle in steady state can be simplified to and treated as a two state system-pre-force generating and force generating states, a sigmoidal temperature dependence of force is expected since increase of temperature favours force 
generation (Davis 1998). Additionally, this force generating transition in isometric muscle has been shown to be before the release of inorganic phosphate in the actomyosin crossbridge/ATPase cycle (Fortune et al. 1991; Kawai and Halvorson 1991; Dantzig et al. 1992; Ranatunga 1999; Sleep et al. 2005). Furthermore, when the crossbridge cycle was altered with added inorganic phosphate $(\mathrm{Pi})$ or MgADP (products released from ATP hydrolysis by crossbridges), the sigmoidal relation between force and temperature was shifted to higher (with $\mathrm{Pi}$; Coupland et al. 2001) or lower temperatures (with MgADP; Coupland et al. 2005).

Although the sigmoidal temperature dependence of force in isometric muscle has been well characterized and its significance discussed (see above), whether or not such a relation can define the temperature dependence of force in shortening muscle, doing external work, is not known. At a given temperature, the active muscle force decreases during steady shortening in a velocity dependent manner leading to the characteristic force-shortening velocity relation (Hill 1938) and this may be due to shortening-enhanced detachment, and cycling, of crossbridges (Huxley 1957), a change in the crossbridge cycle. Morever, the force-shortening velocity relation in mammalian muscle is shown to be temperature sensitive (Ranatunga 1982, 1984) so that the maximal mechanical power output (force $\times$ velocity) at $10^{\circ} \mathrm{C}$ is only $\sim 5 \%$ of that at the physiological temperatures (Ranatunga 1998); also, we reported recently that the force generation induced by a $T$-jump in muscle, although absent in lengthening, is pronounced during steady shortening (Ranatunga et al. 2007). Thus, it would be important to examine the temperature dependence of force in shortening muscle and this was the main aim of the present study. Experimental data for isometric force and force during ramp shortening at different velocities are examined at a range of temperatures in tetanized intact (rat fast) muscle fibre bundles and in maximally Ca-activated skinned (rabbit psoas) fast muscle fibres; previous data from isotonic release experiments on intact rat fast muscle (Ranatunga 1984) are also re-analysed. Our results and analyses show that, for a given velocity, an approximate sigmoidal relation does exist between force and (reciprocal) temperature for shortening muscle but, compared to the isometric case, the relation is shifted to higher temperatures, its slope increased and more so at higher velocities.

\section{Methods}

Intact fibre experiments

Details of various methodologies and procedures used in intact fibre experiments have been reported previously
(Coupland and Ranatunga 2003; Roots et al. 2007). The experiments used small bundles of 5-10 fibres isolated from a foot muscle (flexor hallucis brevis-FHB, containing 90\% type 2 (fast) muscle fibres Coupland and Ranatunga 2003) of adult male rats that were humanely killed with an intra-peritoneal injection of an overdose ( $>200 \mathrm{mg} \mathrm{kg}^{-1}$ body mass) of sodium pentobarbitone (Euthatal, Rhône Mérieux). By means of aluminium foil $T$ clips, attached within $0.2 \mathrm{~mm}$ of the fibre-end to each tendon, a preparation was mounted horizontally between a force transducer (AE 801 element; AME, Horten, Norway) and a servomotor, in a flow-through stainless steel chamber (volume $\sim 2 \mathrm{ml}$ ). The chamber was perfused at $0.5 \mathrm{ml} \mathrm{min}{ }^{-1}$ with a physiological saline solution containing (mM): $\mathrm{NaCl}, 109 ; \mathrm{KCl}, 5 ; \mathrm{MgCl}_{2}, 1 ; \mathrm{CaCl}_{2}, 4$; $\mathrm{NaHCO}_{3}, 24 ; \mathrm{NaH}_{2} \mathrm{PO}_{4}, 1$; sodium pyruvate, 10 and $200 \mathrm{mg} \mathrm{l}^{-1}$ of bovine foetal serum; the solution was continuously bubbled with $95 \% \mathrm{O}_{2}$ and $5 \% \mathrm{CO}_{2}$.

Typically, a fibre bundle was first set-up for recording at $20^{\circ} \mathrm{C}$ and stimulated and the initial length $\left(L_{0}\right)$ adjusted for maximal isometric tetanic tension; the sarcomere length for this setting was $\sim 2.5 \mu \mathrm{m}$, as expected from the relationship between steady state tetanic tension and length for rat muscle fibres (Elmubarak and Ranatunga 1984; ter Keurs et al. 1984). Following an equilibration period of at least $30 \mathrm{~min}$ at $20^{\circ} \mathrm{C}$, isometric tetanic contractions and tetanic contractions with ramp shortening of $20 \% L_{0}$, applied on the tension plateau at five different velocities ranging from 0.2 to $4 L_{0} / \mathrm{s}$ were recorded; the frequency and duration of tetanic stimulation was adjusted as appropriate for the recording (see Coupland and Ranatunga 2003). In each experiment similar recordings were then made at $5^{\circ} \mathrm{C}$ intervals during cooling to $10^{\circ} \mathrm{C}$, warming from 10 to $35^{\circ} \mathrm{C}$ and cooling back to $20^{\circ} \mathrm{C}$; solution temperature changes and control $\left( \pm 1^{\circ} \mathrm{C}\right)$ were achieved by a Peltier device fitted underneath the chamber and was monitored with a thermocouple inside the chamber. In a few experiments the change in the relative position of two markers, placed on the surface of the fibre bundle, was monitored using a position-sensitive detector (see Mutungi and Ranatunga 2001); the two small aluminium foil pieces were placed $0.5-0.7 \mathrm{~mm}$ apart, across the whole width of the bundle and at the force transducer end (excluding the tendon), so that the magnified images of their relative displacement provided a signal for the segment-length change (see Fig. 1c; Roots et al. 2007).

In six fibre bundle experiments in which a coolingwarming-cooling series was recorded, the mean $( \pm$ s.e.m. $)$ fibre length $\left(L_{0}\right)$ and width of the fibre bundles were 2.17 $( \pm 0.11) \mathrm{mm}$ and $148( \pm 2.5) \mu \mathrm{m}$, respectively. The mean ( \pm s.e.m.) tetanic tension $\left(P_{0}\right)$ was $237( \pm 29) \mathrm{kN} \mathrm{m}^{-2}$ at $20^{\circ} \mathrm{C}$; as a ratio of the $P_{0}$ recorded at the beginning, $P_{0}$ at the series end at $20^{\circ} \mathrm{C}$ was $0.88( \pm 0.02)$. 

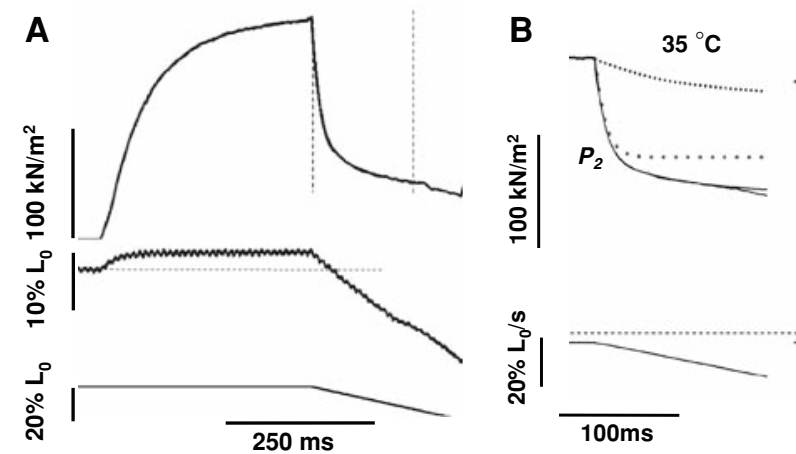

Fig. 1 Tension responses to ramp shortening and their analyses. (a) Sample recordings from a fibre bundle preparation at $20^{\circ} \mathrm{C}$ : the bundle was tetanically stimulated and when the isometric tension reached a plateau (top trace), a ramp shortening of $20 \% L_{0}$ was applied (bottom trace). The length change in a short $(0.6 \mathrm{~mm}$ long) segment of the fibre bundle, nearer the force transducer end but excluding the tendon, was also monitored (middle trace). Note that, due to shortening elsewhere, the segment lengthens $\sim 3 \%$ during the initial tension rise, but shortens uniformly during ramp shortening up to $\sim 12 \% L_{0}$. To define the tension decline, after the inflection (see c) during ramp shortening, the tension record between the two vertical dotted lines is fitted with a double exponential function. (b) Tension responses (upper traces) to ramp shortening at the same velocity, at

\section{Skinned fibre experiments}

As detailed in several previous papers (Ranatunga 1996; Coupland et al. 2001, 2007), these experiments used chemically skinned (using 0.5\% Brij) single fibres from rabbit psoas muscle (fast). The buffer solutions contained $10 \mathrm{mM}$ glycerol-2-phosphate (a temperature-insensitive pH buffer; $\mathrm{pH}=7.1$ ), $4.6 \mathrm{mM}$ MgATP, $12 \mathrm{mM}$ creatine phosphate, $15 \mathrm{mM}$ EGTA (relaxing solution), CaEGTA (activating solution) or HDTA (pre-activating solution), $9 \mathrm{mM}$ glutathione and $\sim 50 \mathrm{mM}$ potassium acetate. The solution compositions were calculated using a computer program for solving multi-equilibria, maintaining ionic strength of $200 \mathrm{mM}$, an excess free $\left[\mathrm{Mg}^{2+}\right]$ of $\sim 1 \mathrm{mM}$ and, in the activating solution, a free $\left[\mathrm{Ca}^{2+}\right]$ of $\sim 0.032 \mathrm{mM}$. $1-2 \mathrm{mg} \mathrm{ml}^{-1}$ creatine kinase ( $\sim 300$ units/ $\mathrm{mg}$, Sigma) was added to buffer solutions before use to decrease $[\mathrm{MgADP}]$. All solutions also contained 4\% Dextran (mol. mass $\sim 500 \mathrm{kDa}$ ) in order to compress the filament lattice spacing to normal dimensions.

The trough assembly was mounted on the stage of an optical microscope and the fibre could be moved and immersed in the different trough solutions (relaxing, preactivating and activating solutions), by means of a lever mechanism. Using thermo-electric modules (Peltier units) fixed on the back wall, and with feedback from a small thermistor, the solution temperature in the front experimental trough could be changed and/or clamped at a desired pre- $T$-jump temperature and was monitored with a
C

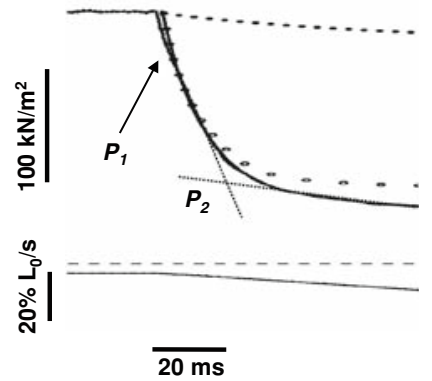

three different temperatures, from another preparation; horizontal dotted line represents zero tension level. The tension change to a ramp shortening occurs in two phases, an initial, larger, fast phase followed by a later slower phase; at $10^{\circ} \mathrm{C}$ the slow phase was not prominent due to low tension reached at this velocity; the initial inflection is not seen at this time scale. A bi-exponential curve is fitted with dotted curves representing the individual components. (c) Tension record at $20^{\circ} \mathrm{C}$ above is displayed at a faster time scale to show the initial inflection ( $P_{1}$ transition, arrow), as first described in frog fibres by Ford et al. (1977); the curve fitting was done to the post-inflection tension trace. Tension at the point of intersection of two linear slopes (dotted lines) was taken as "steady" tension $\left(P_{2}\right)$ for a given shortening velocity (see Roots et al. 2007)

thermocouple. In order to maintain fibre stability, the temperature in the other troughs containing relaxing and pre-activating solutions was kept below $5^{\circ} \mathrm{C}$ by cooling fluid circulating through the trough assembly. The details the technique of laser pulse induced $T$-jumps in muscle fibres have been described fully elsewhere (Ranatunga 1996, 1999). A $T$-jump was induced by a $0.2 \mathrm{~ms}$ laser pulse radiation $(\lambda=1.32 \mu \mathrm{m})$ from a Nd-YAG laser (Schwartz Electro-Optics) that entered the experimental trough through the front glass window. A laser pulse heated the buffer solution in the trough and the muscle fibre bathed in it; the heated fluid/fibre volume ratio was $>2500$. The elevated solution temperature remained constant for at least $\sim 500 \mathrm{~ms}$ and decreased only slowly (half-time longer than $5 \mathrm{~s}$ ) afterwards (see Fig. 1, Ranatunga 1996).

A short fibre segment was attached using nitrocellulose glue between two metal hooks, one connected to the force transducer and the other to the motor. The sarcomere length was set to $2.5 \mu \mathrm{m}$ using $\mathrm{He}-\mathrm{Ne}$ laser diffraction and the fibre width and length were measured under light microscope; fibre length $\left(L_{0}\right)$ was $\sim 2 \mathrm{~mm}$ in most experiments. In these experiments data were collected during warming from $8-9$ to $\sim 30^{\circ} \mathrm{C}$. The force responses to a standard $T$-jump of $3-4^{\circ} \mathrm{C}$ were also examined after a fibre was activated to steady isometric state and then exposed to steady shortening at a standard ramp velocity; one of two velocities were used in experiments, for convenience, referred to as low $\left(0.05-0.09 L_{0} / \mathrm{s}\right)$ and high $\left(0.6-0.9 L_{0} / \mathrm{s}\right)$ 
velocities. Fibres were regularly examined under the microscope and an experiment was terminated when evidence of fibre damage was observed.

Data presented in the paper are from seven fibre experiments; their mean $( \pm$ s.e.m. $)$ maximum isometric $\left(P_{0}\right)$ was $169( \pm 16) \mathrm{kN} \mathrm{m}^{-2}$ at $8-10^{\circ} \mathrm{C}$.

Data recording and analysis

The outputs from the force transducer, the motor (fibre length) and the thermocouple (in skinned fibre experiments) were examined on digital cathode ray oscilloscopes and digital voltmeters and, using CED micro-1401 (Mk II) laboratory interface and Signal 3 software (Cambridge Electronic Design Ltd., Cambridge, UK), stored in a PC based computer. Various measurements were determined offline using Signal software and additional analysis, nonlinear curve fitting etc were performed using Fig P (Biosoft, Durham, USA), Excel (Microsoft), and Mathcad 2000 professional (Mathsoft) software.

Distribution of tension data against temperature was approximately sigmoidal for isometric as well as for ramp shortening conditions and hence, for analytical and descriptive purposes, the multi-state crossbridge cycle in muscle was assumed reducible to be a two-step, two-state system, between no-force (pre-force generating) and forcebearing (generating) crossbridges, as indeed considered for isometric muscle force in previous studies (see Ranatunga 1996; Davis and Epstein 2007). In order to characterise the tension $(\mathrm{P})$-temperature relation, the tension values from each preparation were normalised to its isometric force, at $35^{\circ} \mathrm{C}$ (intact fibres) and at $>25^{\circ} \mathrm{C}$ (skinned fibres); the pooled normalised tensions for a given velocity at different temperatures were then fitted with a sigmoidal curve of the form (see Coupland et al. 2001):

$\mathrm{P}=\mathrm{P}_{\max }-\mathrm{P}_{\max } /\left[1+\exp \left\{-(\Delta \mathrm{H} / \mathrm{R})\left(1 / \mathrm{T}-1 / \mathrm{T}_{0} \cdot 5\right)\right\}\right]$

where $P_{\max }$ is maximal force, $R$ is $8.314 \mathrm{~J} \mathrm{~mol}^{-1} \mathrm{~K}^{-1}, T$ is reciprocal absolute temperature and $T_{0.5}$ is temperature corresponding to $0.5 P_{\max }$, where $\Delta \mathrm{G}$ (free energy change) is minimal. From the fitted curve, $\Delta H$ (activation enthalpy change) was obtained and $\Delta S$ (entropy change) calculated as $\Delta H / T_{0.5}$. The data were also examined in the form of a vant Hoff's plot, by plotting $P /\left(P_{\max }-P\right)$ on a logarithmic ordinate against (1/T) (see Brown 1957):

$\log \left(P /\left(P_{\max }-P\right)\right)=(-\Delta H / R T)+(\Delta S / R)$

and $\Delta H$ (in $\left.\mathrm{kJ} \mathrm{mol}^{-1}\right)$ and $\Delta S\left(\mathrm{~J} \mathrm{~mol}^{-1} \mathrm{~K}^{-1}\right)$ determined from the linear slope and the intercept, respectively. (Note that the units for $\Delta H$ were mistakenly given as $\mathrm{kJ} \mathrm{K}^{-1}$ and $\mathrm{kJ} \mathrm{mol}^{-1} \mathrm{~K}^{-1}$ in our previous publication-Coupland et al. 2001).
Using the isotonic release method in a previous study (Ranatunga 1984), we determined the force-shortening velocity relation of rat fast and slow muscles at different temperatures $\left(10-35^{\circ} \mathrm{C}\right)$. The normalised tension data collected for various temperatures $(n=6-10)$ for fast muscle, in that study, were also re-analysed to examine the forcetemperature relation for various shortening velocities as above. Other particulars about the analyses will be referred to in describing the results.

Simulation of force-temperature relation

A minimal actomyosin ATPase/crossbridge cycle which was used previously to simulate Pi effects (Dantzig et al. 1992) and temperature effects on isometric force (Coupland et al. 2001) was extended to examine the temperaturedependence of steady force in shortening muscle. It consisted of three actomyosin/crossbridge states (1-3) in a linear scheme (Scheme 1) as:

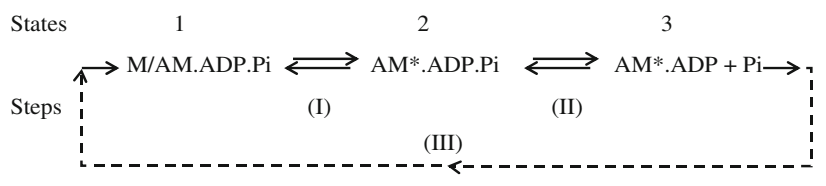

Scheme 1 A minimal actomyosin/crossbridge cycle

According to the scheme, state 1 (M/AM.ADP.Pi) is a no force state (pooled pre-force generating and detached states) whereas states 2 and 3 (AM*ADP.Pi and AM*ADP) are high (and equal) force generating states; the sum of the fractional occupancy of these two states was taken to represent isometric force and it was calculated as,

Force $_{(\text {isom })}=\operatorname{Occ}(2+3)=\left(k_{\mathrm{a}} k_{\mathrm{d}}[\mathrm{Pi}]+k_{\mathrm{a}} k_{\mathrm{e}}+k_{\mathrm{a}} k_{\mathrm{c}}\right) /$ total,

where total is $\left(k_{\mathrm{a}} k_{\mathrm{d}}[\mathrm{Pi}]+k_{\mathrm{a}} k_{\mathrm{e}}+k_{\mathrm{a}} k_{\mathrm{c}}\right)+k_{\mathrm{b}} k_{\mathrm{d}}[\mathrm{Pi}]+$ $k_{\mathrm{c}} k_{\mathrm{e}}+k_{\mathrm{b}} k_{\mathrm{e}}$.

The steady isometric tension behaviour at different Pilevels and temperatures are predicted by changes in two "equilibria" (steady-states) in the cycle, step I $\left(k_{\mathrm{a}} / k_{\mathrm{b}}\right)$ and step II $\left(k_{\mathrm{c}} / k_{\mathrm{d}}\right)$, where step I is temperature-sensitive and step II the Pi-release/binding step. Essentially as in our previous studies (Coupland et al. 2001; Ranatunga et al. 2007), the forward rate constant $k_{\mathrm{a}}$ in step I was $20 \mathrm{~s}^{-1}$ at $10^{\circ} \mathrm{C}$, and the temperature effects were simulated (for $5^{\circ} \mathrm{C}$ temperature intervals between 0 and $40^{\circ} \mathrm{C}$ ) by changing $k_{\mathrm{a}}$ with a $Q_{10}$ of 4 ; the reverse $k_{\mathrm{b}}$ was $120 \mathrm{~s}^{-1}$. In step II, $k_{\mathrm{c}}$, the Pi-release, was $10^{3} \mathrm{~s}^{-1}, k_{\mathrm{d}}$ for Pi-binding was $1.0 \times 10^{-5} \mathrm{~m}^{-1} \mathrm{~s}^{-1}$, and was changed to simulate $\mathrm{Pi}$ effects. Step III $\left(k_{\mathrm{e}}\right)$ was irreversible-representing all the steps (including detachment, hydrolysis and attachment) necessary to reprime the crossbridges for the next cycle and for isometric case $k_{\mathrm{e}}$ was $10 \mathrm{~s}^{-1}$. 
Since an increased detachment rate is generally assumed for shortening muscle (Huxley 1957; He et al. 2000; Ranatunga et al. 2007), $k_{\mathrm{e}}$ was increased to values between 12.5 and $640 \mathrm{~s}^{-1}$ to simulate shortening and, assuming an exponential dependence of $k_{\mathrm{e}}$ on velocity, $\ln \left(k_{\mathrm{e}} / k_{\mathrm{e} \text { (isom) }}\right)$ was taken as velocity in $L_{0} / \mathrm{s}$. In order to simulate the temperature-dependence of steady force during shortening at a given velocity, the occupancy estimates as above and representing isometric force, were further transformed in two ways. Firstly, since at a certain critical low temperature $\left(T_{\mathrm{c}}\right)$, a given velocity would represent the $\mathrm{V}_{\max }$, where force is zero-due to negative and positive strained crossbridges being equal, the occupancy at $T_{\mathrm{c}}$ was subtracted from $\operatorname{Occ}(2+3)$ for that velocity at all the temperatures; from previous experiments $T_{\mathrm{c}}$ was known for some velocities and the $\operatorname{Occ}(2+3)$ at $T_{\mathrm{c}}$ was directly known from the calculations, for other velocities (e.g. low velocities) it was approximated. Secondly, since the crossbridges would be exposed to negative strain during shortening, the average force per crossbridge would be less than in isometric. Thus, the steady force during shortening at a given velocity at different temperatures was calculated as,

Force $_{(\text {short })}=\left[\operatorname{Occ}(2+3)-\operatorname{Occ}(2+3)_{T_{\mathrm{c}}}\right] \times r$,

where $\mathrm{r}$ ranged from 1 (isometric) to 0.4 (high velocity); $\mathrm{r}$ decreased linearly with increase of velocity to approximately fit the experimental data. Although the kinetic scheme does not separately identify detached states, the two transformations above amount to a decrease of attached crossbridges, and of positive-strain in them, as compared with isometric case, broadly consistent with the experimental finding that stiffness is decreased with increase of shortening velocity (Julian and Morgan 1981; Ford et al. 1985).

\section{Results}

Experiments on intact fibres

\section{Tension response to ramp shortening and analyses}

The superimposed tension traces shown in Fig. 1a illustrate the general features of the tension response to a ramp shortening from an intact fibre bundle from the rat flexor hallucis brevis (FHB) muscle; the fibre bundle-ends were held isometric until the tetanic tension-plateau, $P_{0}$, and then a ramp shortening of $20 \% L_{0}$ (lowermost trace) was applied. The change in length of a segment of the bundle near the force transducer end (middle trace) shows a basic similarity with the applied ramp shortening; the late increase of slope may be due to decrease of filament overlap after $>12 \%$ shortening (see Fig. 1 for details). During a ramp shortening, the tension (uppermost trace) falls rapidly initially (to an inflection) and then undergoes a gradual transition (referred to as $P_{2}$-Roots et al. 2007) after which tension declines more slowly. The tension $P_{2}$ at a given velocity was estimated as the tension at the point of intersection between two linear slopes, as shown in the inset (Fig. 1c); the inset, on an expanded time scale, also shows the occurrence of the inflection at the beginning of the tension decline as reported in previous studies (Ford et al. 1977; Roots et al. 2007); this represents the force generating transition in the attached (pre-stroke) crossbridges on exposure to negative strain. The post-inflection tension decline during a ramp shortening was fitted with a double exponential function (see Fig. 1) to isolate the time course of the faster, major, component from the slower subsequent decay. Figure $1 \mathrm{~b}$ shows the traces and component curves obtained from a preparation at three different temperatures using one velocity. With increase of temperature from 10 to $35{ }^{\circ} \mathrm{C}$, the amplitude of the faster component shows temperature-sensitivity and the rate of the (faster) tension decline increases slightly. Both the isometric tension (before the ramp) and the "steady" shortening tension $P_{2}$, or the tension reached after the faster exponential component $\left(\sim P_{2}\right)$, increase markedly with temperature.

\section{Temperature dependence of force during ramp shortening}

In experiments on six fibre bundles, the tension during steady shortening at five different ramp velocities $(0.25,0.4$, $0.8,1.9$ and $\left.3.6 L_{0} / \mathrm{s}\right)$ and the isometric tension $\left(P_{0}\right)$ were determined, and analysed as above, at six different temperatures (see "Methods"). Figure 2a shows isometric force (as stress) and stiffness data plotted against temperature; stiffness was estimated from the linear slope of initial tension decline at the onset of the highest ramp shortening velocity (3.6 $L_{0} / \mathrm{s}$, see Fig. 2). Assuming that there is no crossbridge detachment prior to $P_{1}$-inflection (see above), the stiffness data shows that a two-fold increase of isometric tension between $10-35^{\circ} \mathrm{C}$ is not associated with an increase of number of crossbridge attachments. Examination of the force-shortening velocity per se was not the main concern of this study; nevertheless, when the $P_{2}$ tension data for the five standard velocities were examined to define the forceshortening velocity curve at each temperature (see Fig. 2b), the curves showed a higher $\mathrm{V}_{\max }$ and a lower curvature at the higher temperatures. The $\mathrm{V}_{\max }$ by extrapolation to zero force was $\sim 2 L_{0} / \mathrm{s}$ at $10^{\circ} \mathrm{C}$ and it increased to $>10 L_{0} / \mathrm{s}$ at $35^{\circ} \mathrm{C}$. As shown in Fig. $2 \mathrm{c}$, a velocity of $\sim 3.6 L_{0} / \mathrm{s}$ was within the range for producing the maximum power output at $35^{\circ} \mathrm{C}$ (physiological temperatures); the maximum power was 
Fig. 2 Isometric force, stiffness and force-shortening velocity curves at different temperatures. (a) The mean isometric force per crosssectional area ( \pm s.e.m., filled squares) recorded from 6 fibre bundles at different temperatures $(1 / T)$; the errors in these absolute force values become reduced when force from different fibre bundles is normalized to a particular temperature, as in Fig. 3a. A sigmoidal curve is fitted as in Fig. 3. Mean ( \pm s.e.m.) $P_{0}$ at $35^{\circ} \mathrm{C}$ was $282 \pm 35 \mathrm{kN} / \mathrm{m}^{2}$. Open symbols show the mean (s.e.m.) stiffness data ( $n=6-18$ per symbol); stiffness was determined as slope of the initial tension decline (before $P_{1}$ inflection-see Fig. 1c) divided by the velocity, from the highest velocity $\left(\sim 3.6 L_{0} / \mathrm{s}\right)$, and is given as $P_{0}\left(10^{\circ} \mathrm{C}\right) / L_{0}$. Note that an average force increase of two-fold in warming from 10 to $35^{\circ} \mathrm{C}$ is not associated with a stiffness change (slope of the fitted line is not significant). (b) The pooled $P_{2}$ force data in Fig. 3 (i.e. for five shortening velocities) are shown as forcevelocity curves at the six different temperatures (different symbols; $10^{\circ} \mathrm{C}$ lower most curve and $35^{\circ} \mathrm{C}$ uppermost curve). The mean force values (in $\mathrm{kN} / \mathrm{m}^{2}$ ) are plotted against the velocity (V) on a negative abscissa. From the fitted Hill curves (1938) the curvature is less and the $\mathrm{V}_{\max }$ ( $\mathrm{V}$ extrapolated to zero force) is higher at the higher temperatures, as reported previously (Ranatunga 1984). (c) The mechanical power (force $\times$ velocity, in $\mathrm{kW} / \mathrm{m}^{3}=\mathrm{W} / \mathrm{l}$ ) versus velocity curves from the same data. Note that the maximum power is $\sim 230 \mathrm{~kW} / \mathrm{m}^{3}$ at $35^{\circ} \mathrm{C}$ (V of $\sim 3.6 L_{0} / \mathrm{s}$ ) and it is $\sim 13 \mathrm{~kW} / \mathrm{m}^{3}$ (V of $\left.0.27 \mathrm{~L}_{0} / \mathrm{s}\right)$ at $10^{\circ} \mathrm{C}$

$\sim 230 \mathrm{~kW} \mathrm{~m}^{-3}\left(=230 \mathrm{~W} \mathrm{l}^{-1}\right)$. At $10^{\circ} \mathrm{C}$, the power is $\sim 13 \mathrm{~kW} \mathrm{~m}^{-3}$ (velocity, $\sim 0.3 L_{0} / \mathrm{s}$ ), i.e. reduced to $5-6 \%$ of that at $35^{\circ} \mathrm{C}$. The above findings are basically similar to those reported for rat fast (e.d.l.) muscle in previous studies that used the isotonic release method in determining the force-shortening velocity curve for rat fast muscle (see Ranatunga 1984, 1998).

Figure $3 \mathrm{a}$ shows pooled (mean \pm s.d.) data for the temperature dependence of tension during steady shortening $\left(P_{2}\right)$ at the five velocities and of the isometric tension; for pooling the data from different experiments, tension $(P)$ was normalised to the isometric tension at $35^{\circ} \mathrm{C}\left(P_{0(35)}\right)$ and are plotted against reciprocal absolute temperature $\left(10^{3} / T\right)$. Each set of data is fitted with a sigmoidal curve (see "Methods"). The curve fit for isometric data gives a $T_{0.5}$ of $\sim 10^{\circ} \mathrm{C}, \Delta H$ (activation enthalpy change) of $\sim 100 \mathrm{~kJ} \mathrm{~mol}^{-1}$ and $\Delta S$ (activation entropy change, as $\Delta H /$ $T_{0.5}$ ) of $\sim 360 \mathrm{~J} \mathrm{~mol}^{-1} \mathrm{~K}^{-1}$; in shortening, these values are increased with velocity so that at $3.6 L_{0} / \mathrm{s}$ (open circles, bottom curve), $T_{0.5}$ is $\sim 28^{\circ} \mathrm{C}, \Delta H \sim 200 \mathrm{~kJ} \mathrm{~mol}^{-1}$ and $\Delta S \sim 700 \mathrm{~J} \mathrm{~mol}^{-1} \mathrm{~K}^{-1}$. Figure $3 \mathrm{~b}$ illustrates the same mean data with the force normalised to the maximum $\left(P_{\max }\right)$ in each case; the shift of the curves to higher temperatures as the shortening velocity is increased is clearly seen. If the sigmoidal temperature dependence is due to the fact that a force generating muscle can be simplified to a two-step (force generation/force loss) system in equilibrium, a vant Hoff plot can be constructed for each set of data (see Brown 1957); Fig. 3c are vant Hoff plots using the mean data (see Methods), where $P /\left(P_{\max }-P\right)$ is plotted on a logarithmic ordinate against $1 / T$. Despite the

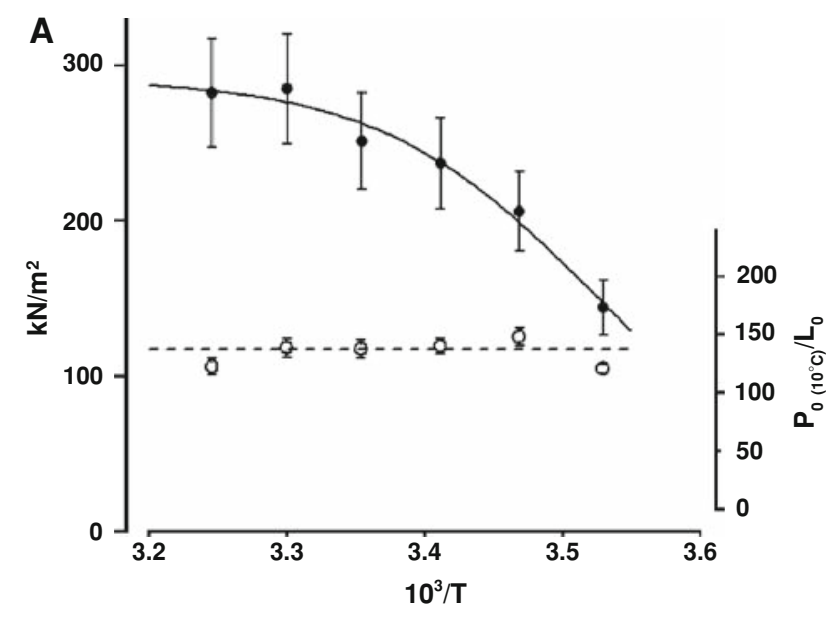

B

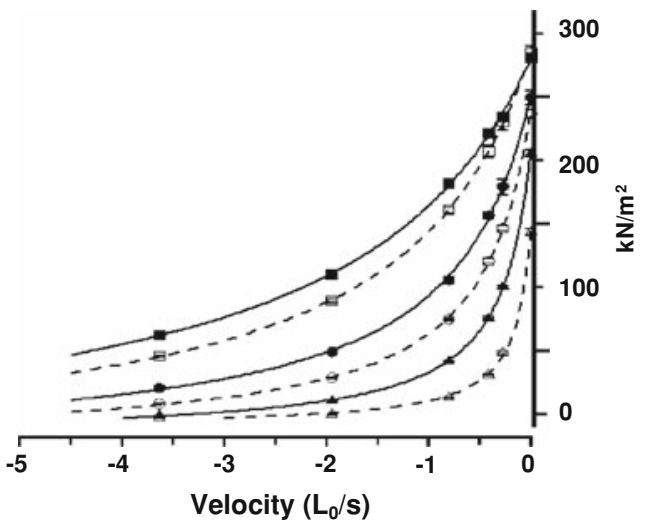

C

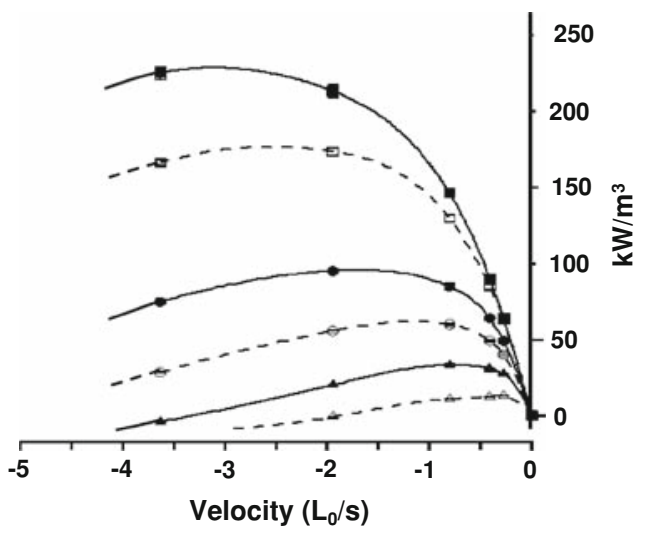

scatter in them, the data shows an approximate linear relation for each case; compared to the isometric case (filled squares), the slope $(\Delta H)$ and the intercept at $1 /$ $T_{0}=$ zero $(\Delta S / R)$ are increased with shortening velocity.

\section{Temperature dependence of shortening force from isotonic release experiments}

In a previous study (Ranatunga 1984), we examined the force-shortening velocity relation in rat fast (extensor digitorum longus) muscle using the isotonic release method, where the steady velocity was measured at 

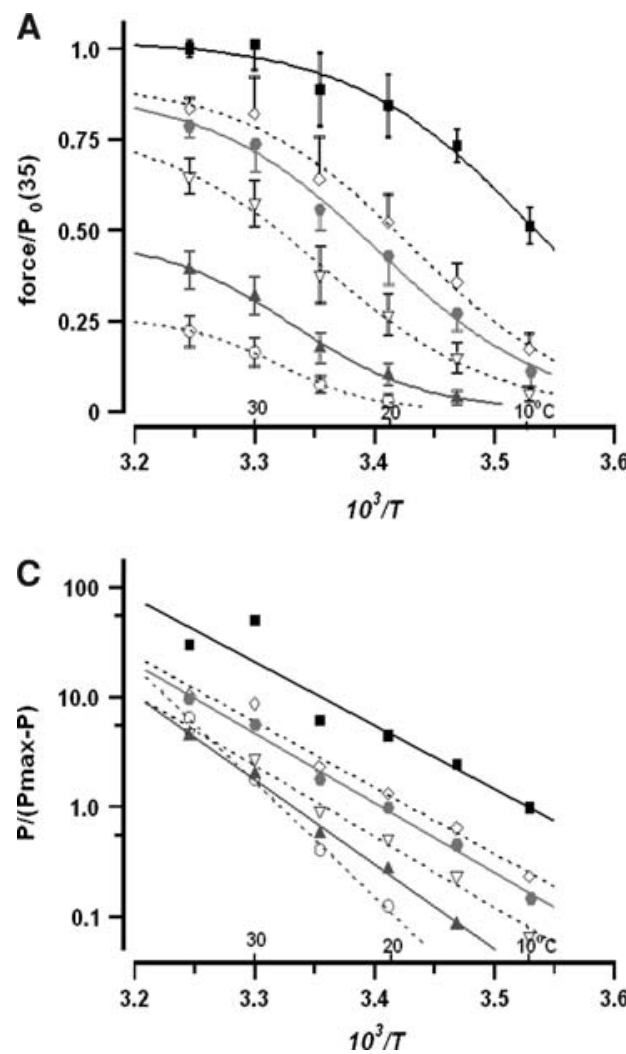

Fig. 3 Temperature dependence of active force during ramp shortening. The data from six FHB fibre bundles in each of which tension responses to 5 ramp shortening velocities were recorded at six different temperatures during warming and cooling (range $10-35^{\circ} \mathrm{C}$, see "Methods"). (a) The tension during shortening at each velocity (i.e. tension at the $P_{2}$ transition) was normalised to the isometric tension $\left(P_{0}\right)$ at $35^{\circ} \mathrm{C}$ and the mean ( \pm s.d., $n=6-18$ per symbol) values are plotted against reciprocal absolute temperature $\left(10^{3} / T\right)$; the velocities were $0.27,0.4,0.8,1.9$ and $\left.3.6 L_{0} / \mathrm{s}\right)$. The filled squares represent mean isometric tension data (same data as in Fig. 3 but with \pm s.d.) from the same experiments $(n=40-120$ per symbol). Note that, in all cases, the tension increases with warming and a sigmoidal

constant force levels and data defining the force-velocity curve were obtained for temperatures ranging from 10 to $35^{\circ} \mathrm{C}$; the isometric force increase in warming from 10 to $35^{\circ} \mathrm{C}$ was $\sim 2$-fold (Ranatunga and Wylie 1983), as found in the previous (Coupland and Ranatunga 2003) and present experiments on fast FHB fibres. It is therefore of interest to re-analyse the data from those isotonic release experiments to determine, for a number of shortening velocities, the temperature dependence of isotonic force. This was done using the mean data for the normalised force-velocity curves given in Table 1 in Ranatunga (1984) and temperature-dependence of $P_{0}$ given in Fig. 3b in Coupland and Ranatunga (2003). From these reanalyses, the data for isometric (filled squares) and five shortening velocities $\left(0.25-5 L_{0} / \mathrm{s}\right)$ are shown in Fig. $4 \mathrm{a}$ where the presentation is similar to Figs. 3a, 4b shows the vant Hoff's plots of the same data. The basic features described for the

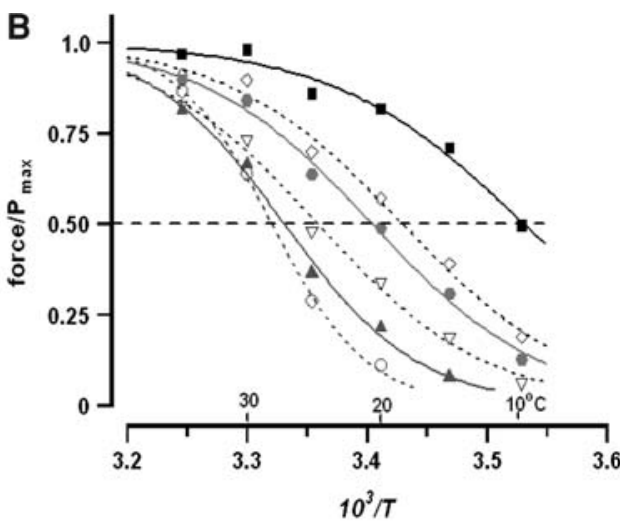

curve (see "Methods") can approximately describe the distribution of each set of data. (b) The mean tension data are normalised to the maximum force $\left(P_{\max }\right)$ from curve fit to each data set; note the temperature for half-tension is $\sim 10^{\circ} \mathrm{C}$ for isometric tension (as found previously, Ranatunga and Wylie 1983; Coupland and Ranatunga 2003) but it is higher at higher velocities (curves shifted to the left, higher temperatures). (c) Linear van't Hoff plots on the same data; force/(maximum force-force) ratio (see Brown 1957) is plotted. Each set of data is approximately linearly distributed and the slope of the linear regression increases with velocity from $\Delta H$ of $\sim 110 \mathrm{~kJ} \mathrm{~mol}^{-1}$ for isometric data to $\sim 200 \mathrm{~kJ} \mathrm{~mol}^{-1}$ for shortening at $\sim 4 L_{0} / \mathrm{s} ; \Delta S$ (from the intercept) increases from $\sim 400$ to $\sim 700 \mathrm{~J} \mathrm{~mol}^{-1} \mathrm{~K}^{-1}$

temperature dependence of force in ramp shortening experiments (Fig. 3) are also seen in the isotonic release experimental data (Fig. 4).

A summary of the various thermodynamic parameters extracted from analyses of force at different temperatures, as illustrated in Figs. 3, 4, is shown in Fig. 5a, c (ramp shortening) and in Fig. 5b, d (isotonic release); they are plotted against shortening velocity (on a negative abscissa). Figure $5 \mathrm{a}$ and $\mathrm{b}$ show that the temperature $T_{0.5}$ at which force is half-maximal in the sigmoidal curve increases from $\sim 10^{\circ} \mathrm{C}$ for isometric $(\mathrm{V}=0)$ to $\sim 28-30^{\circ} \mathrm{C}$ when shortening at 3-5 $L_{0} / \mathrm{s}$, velocity that produces the maximal power at physiological temperature $\left(\sim 35^{\circ} \mathrm{C}\right)$. Figure $5 \mathrm{c}$ and d show that both $\Delta H$ and $\Delta S$ increase with increase of shortening velocity; the increase from isometric to a velocity of 3-5 $L_{0} / \mathrm{s}$ is about two-fold. Also, the increase with velocity of $\Delta H$ and of $\Delta S$ are such that, for $35^{\circ} \mathrm{C}$ 


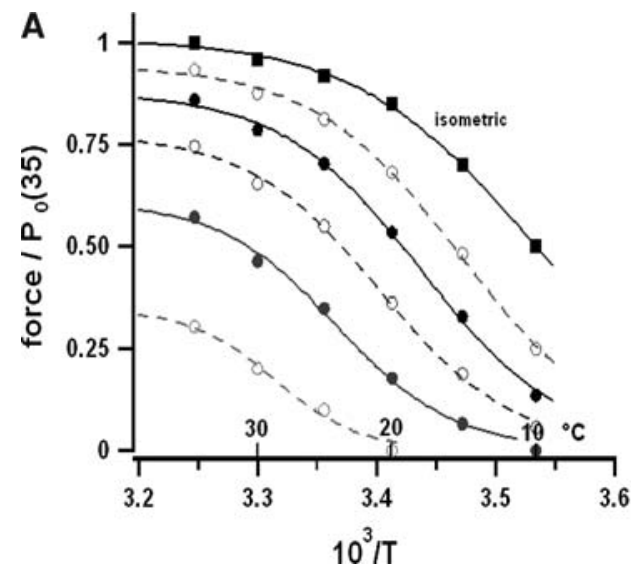

Fig. 4 Temperature dependence of isotonic force from isotonic release experiments. A re-analysis of previous experimental data on the force-shortening velocity relation at different temperatures (Ranatunga 1984); this study, on a rat fast muscle, measured the shortening velocity at different constant isotonic force levels (the isotonic release method) at $10,15,20,25,30$ and $35^{\circ} \mathrm{C}$. (a) Using the mean data defining the normalised force versus shortening velocity curves for various temperatures $\left(\mathrm{a} / P_{0}\right.$ ratio of Hill's equation and $\mathrm{V}_{\max }$, see Table 1 in Ranatunga 1984) and the $\sim 2$-fold (sigmoidal) increase of isometric force on warming from 10 to $35^{\circ} \mathrm{C}$ (Ranatunga and Wylie 1983; Coupland and Ranatunga 2003), the isotonic force at 5 different shortening velocities (range $0.25-5 L_{0} / \mathrm{s}$ ) were calculated for different temperatures. The computed isotonic force (symbols) at

(i.e. $T=308 \mathrm{~K}$ ), $\Delta H$ and $T \Delta S$ are $100-110 \mathrm{~kJ} \mathrm{~mol}^{-1}$ in isometric and they increase to $200-210 \mathrm{~kJ} \mathrm{~mol}^{-1}$ for maximum power production.

It may be argued that the characteristic differences in the activation thermodynamic parameters $(\Delta H$ and $\Delta S)$ seen between isometric and steady shortening, arise during the time course of tension decline from isometric to the steady shortening state. Figure 6 shows, as an Arrhenius plot, the temperature dependence of the apparent rate of tension decline (the reciprocal time constant, $\tau$, from the faster of the two exponential components in curve fit, Fig. 1) at the five ramp shortening velocities. There is much variability (error bars) at the low temperatures for high velocities, presumably due to force declining to zero. Nevertheless, the results show that at any given temperature the rate is higher at higher velocities but that, in general, the rate of shortening induced tension decline is not very temperature sensitive; the slopes of the fitted lines correspond to a $Q_{10}$ of $<1.5$ for $0.25 L_{0} / \mathrm{s}$ (lowermost curve) and it decreases with increase of velocity to $Q_{10}$ of $<1$ for $3.6 L_{0} / \mathrm{s}$ (top curve).

\section{Experiments on skinned (rabbit psoas) muscle fibres}

The significance of the sigmoidal temperature dependence of isometric tension in relation to the crossbridge cycle has been fully considered in relation to data from maximally Caactivated skinned fibres (see Davis 1998; Coupland et al.

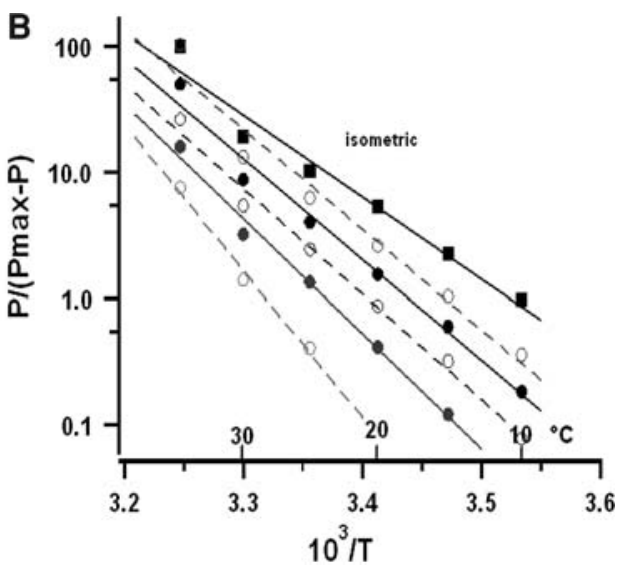

the 5 shortening velocities and the isometric force (filled squares) are plotted, as a ratio of isometric force at $35^{\circ} \mathrm{C}$, against reciprocal absolute temperature; a sigmoidal curve is fitted to the set of data for a given velocity. Note that, force increases with increase of temperature in all cases and, with increase of velocity (from right to left), the sigmoidal curves are shifted to higher temperatures - as obtained with ramp shortening (Fig. 3a). (b) The linear van't Hoff plots made on the data; the slope of the linear regression increases with velocity so that $\Delta H$ increases from $\sim 125 \mathrm{~kJ} \mathrm{~mol}^{-1}$ for isometric to $\sim 220 \mathrm{~kJ} \mathrm{~mol}^{-1}$ for velocity of $\sim 5 L_{0} / \mathrm{s} ; \Delta S$ increases from $\sim 400 \mathrm{~J} \mathrm{~mol}^{-1} \mathrm{~K}^{-1}$ to $\sim 750 \mathrm{~J} \mathrm{~mol}^{-1} \mathrm{~K}^{-1}$, basically similar to the findings from ramp shortening (Fig. 3c)

2001). Although our recent experiments (Ranatunga et al. 2007) showed that the endothermic ( $T$-jump) force generation was evident during low velocity ramp shortening, (see "Introduction"), whether the sigmoidal relation is velocity dependent is not known. Since getting reliable and reproducible data from skinned fibres at high temperatures is difficult, the experimental protocol was different to that for intact fibres and limited to two velocities; a fibre is Caactivated at low temperature $\left(<9^{\circ} \mathrm{C}\right)$ and rapidly warmed to obtain data at higher temperature (see "Methods" and also, Coupland et al. 2001). Figure 7a and b show tension traces (upper panels) from two experiments; in each case, a ramp shortening at a given velocity was applied at different temperatures; also, a small $T$-jump (see "Methods") was induced during steady shortening to examine whether endothermic force is evident. $T$-jump induces a clear tension rise at both velocities, suggesting that tension decline during shortening contains a temperature-sensitive component.

Figure 7c shows the tension data for isometric (filled symbols) and shortening conditions at two different velocity ranges (see Fig. 7) collected from experiments on seven fibres; this includes previous data from Ranatunga et al. (2007) but they were re-analysed for comparison with intact fibre experiments (Fig. 3). The data show that a sigmoidal curve can describe the tension data not only for isometric (soild symbols) but also for shortening conditions (open symbols); from the curves, $T_{0.5}$ was $\sim 8^{\circ} \mathrm{C}$ for isometric (similar to Coupland et al. 2001) and it increased to 


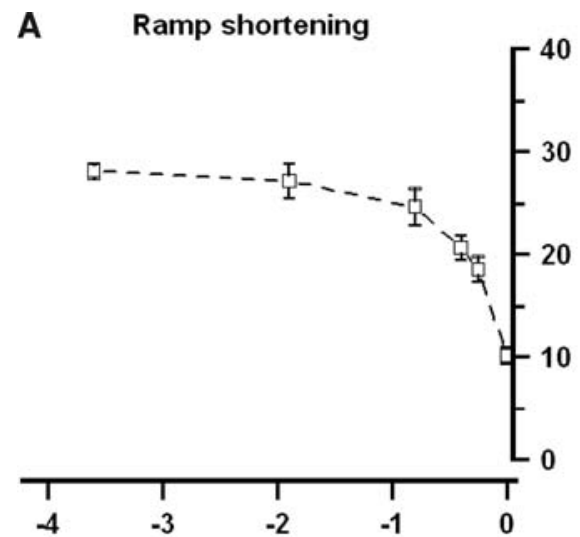

c

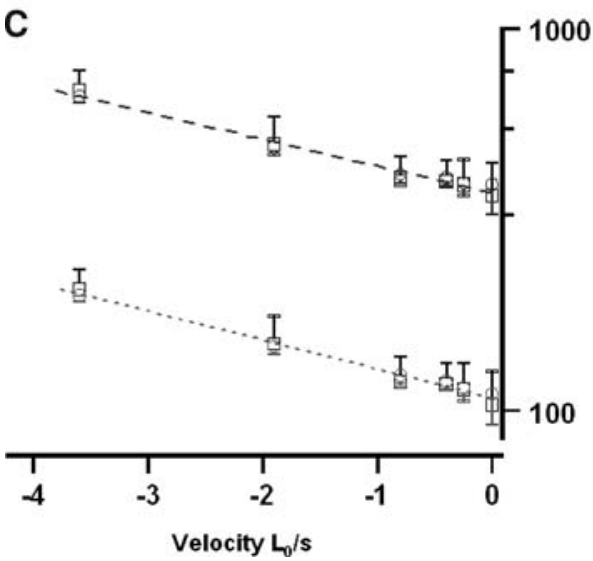

Fig. 5 Thermodynamic parameters for different shortening velocities. A summary illustration of the indices extracted from the analyses shown in Figs. 3 and 4; the error bars are \pm (or + or - ) s.e. associated with the calculations or measurements. $\mathbf{a}$ and $\mathbf{c}$ are from the ramp shortening experiments and $\mathbf{b}$ and $\mathbf{d}$ from the isotonic release experiments. Data are plotted against shortening velocity $\left(L_{0} /\right.$ s) on the abscissa; a shortening velocity of $\sim 3-5 L_{0} / \mathrm{s}$ leads to maximal mechanical work production at $35^{\circ} \mathrm{C}$ in rat fast muscle (see Fig. 2b and also Ranatunga 1998). (a, b) The temperature at which

$\sim 13^{\circ} \mathrm{C}$ for higher velocity $\left(0.5-0.9 \quad L_{0} / \mathrm{s}\right), \Delta H$ was $\sim 100 \mathrm{~kJ} \mathrm{~mol}^{-1}$ for isometric and $\sim 140 \mathrm{~kJ} \mathrm{~mol}^{-1}$ for the same shortening velocity (see other details in Fig. 7). Thus, although the data are limited to two velocity ranges (low and high) and the temperature range is $<30^{\circ} \mathrm{C}$, the basic trends shown in intact fibre experiments are clear in these experiments.

Figure 8 illustrates, in the form of Arrhenius plots, the kinetic data obtained for the two shortening velocity ranges; the data distribution for each case appears linear within the temperature range. As found in intact fibre experiments in Fig. 6, the apparent rate of tension decline (open symbols) is higher for higher shortening velocity (B) than for low velocity (A) but their temperature sensitivities are low, $Q_{10}$ 0.85-1.0. $T$-jump tension rise (filled symbols) is faster with higher velocity, but both have higher temperature sensitivity $Q_{10}$ s of 1.7 (higher velocity) and 2.7 low (velocity) than for tension decline. Interestingly, with
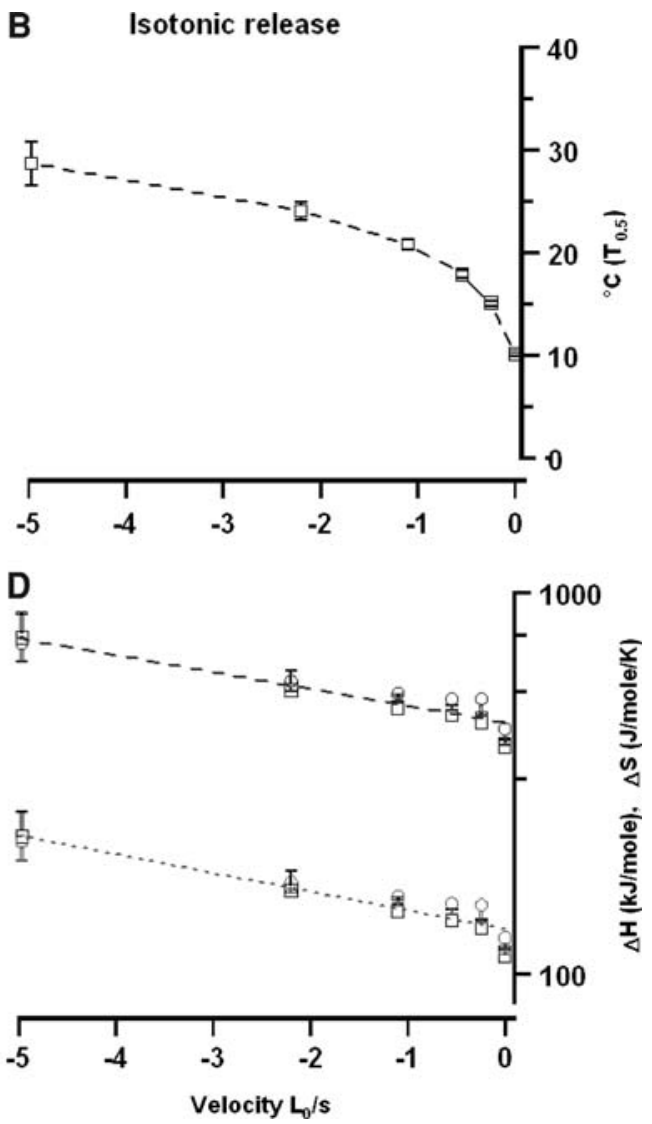

force, in a sigmoidal curve, was half-maximal $\left(T_{0.5}\right.$ in $\left.{ }^{\circ} \mathrm{C}\right)$ increases with increase of shortening velocity; thus, temperature at which free energy change, $\Delta \mathrm{G}$, is minimal is higher in shortening muscle. (c, d) Enthalpy change $\left(\Delta H\right.$ in $\left.\mathrm{kJ} \mathrm{mol}^{-1}\right)$-lower set of data in both frames-and entropy change $\left(\Delta S\right.$ in $\left.\mathrm{J} \mathrm{mol}^{-1} \mathrm{~K}^{-1}\right)$ - upper set of data-are plotted on logarithmic ordinates. Note that, in the two different types of experiments, both $\Delta H$ and $\Delta S$ increase more or less in parallel with increase of shortening velocity; values from sigmoidal curve fit and from vant Hoff's plots (different symbols) are similar

high velocity shortening, although the rate of $T$-jump tension rise is higher than in isometric fibres (Bershitsky and Tsaturyan 1990), it has a lower temperature sensitivity.

\section{Discussion}

The present study extends previous findings on the temperature dependence of force in isometric muscle to temperature dependence of force in shortening muscle, i.e. when muscle is performing external work. The main findings from the study are listed and briefly discussed below and some general aspects related to the findings considered later.

Findings from the present study

(1) The sigmoidal curve for isometric tension versus temperature $(1 / T)$ has a half-maximal tension at a temperature 


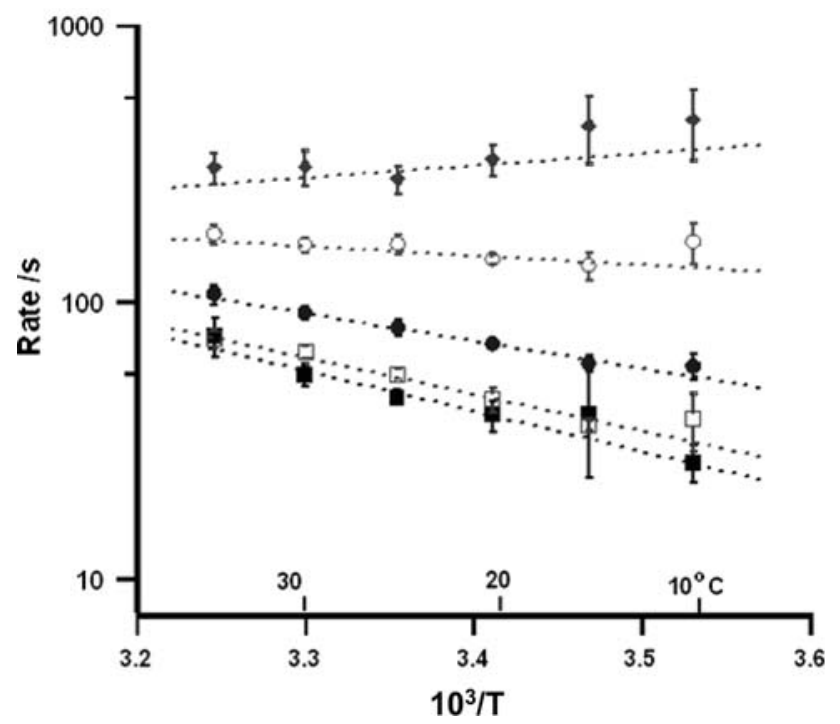

Fig. 6 Temperature dependence of the apparent rate of tension decline during ramp shortening. Arrhenius plots of the rate of the tension decline (reciprocal of the time constant for the faster exponential component) at 5 different velocities of shortening (range 0.25-3.6 $L_{0} / \mathrm{s}$ - different symbols from bottom to top); the tension decline is faster higher the velocity at any given temperature. Mean $( \pm$ s.e.m.) are displayed and lines are the fitted regressions to the pooled data $(n>50)$; the slopes give $Q_{10}$ s ranging from 1.47 at 0.25 $L_{0} / \mathrm{s}$ (filled squares) to 0.89 at $\sim 4 L_{0} / \mathrm{s}$ (filled diamonds and negative slope)

$T_{0.5}$ of $8-10^{\circ} \mathrm{C}$, as reported in previous studies (Coupland et al. 2001; Coupland and Ranatunga 2003); on average, the tension at $\sim 10^{\circ} \mathrm{C}$ is $\sim 150 \mathrm{kN} \mathrm{m}^{-2}$ and it is increased to $\sim 300 \mathrm{kN} \mathrm{m}^{-2}$ at the physiological temperatures $\left(\sim 35^{\circ} \mathrm{C}\right)$. The stiffness remains unchanged at different temperatures (Fig. 2a) and hence, the temperature dependent change of force is due to a shift in the equilibrium between low-force and high-force attached states with little change in the total number of attachments; this is not inconsistent with the finding from single-molecule experiments of Kawai et al. (2006) at different temperatures have demonstrated that the force each crossbridge generates is independent of temperature. From different analyses, the activation enthalpy change $\Delta H$ is $103-110 \mathrm{~kJ} \mathrm{~mol}^{-1}$ and entropy change $\Delta S$ is 364-391 $\mathrm{J} \mathrm{mol}^{-1} \mathrm{~K}^{-1}$; these values are remarkably similar to those derived by Zhao and Kawai (1994) for the force generating equilibrium in the isometric crossbridge cycle $\left(\Delta H 103 \mathrm{~kJ} \mathrm{~mol}^{-1}\right.$ and $\Delta S 357 \mathrm{~J} \mathrm{~mol}^{-1} \mathrm{~K}^{-1}$, their Table 3$)$, from sinusoidal perturbation experiments on skinned (rabbit psoas) fibres.

(2) The steady force during ramp shortening at a given velocity also increases on warming and, to a first approximation, the data can be described by a sigmoidal relation; the basic features and trends were clear in the data from isotonic release experiments and from Ca-activated skinned fibre experiments. In comparison to the isometric curve, the sigmoidal curve for force versus temperature in shortening muscle is shifted to higher temperatures, in a velocity dependent manner (Figs. 3, 4, 7); $\Delta H$ (and $\Delta S$ ) determined from different analyses is increased, also in a velocity dependent manner (Fig. 5). It is noteworthy that, within the temperature range of $10-35^{\circ} \mathrm{C}$, the vant Hoff's plots $(\sim \ln (\mathrm{K})$ vs. $1 / T$, Figs. $3 \mathrm{c}, 4 \mathrm{~b})$ were approximately linear for each velocity in shortening muscle and for isometric muscle; this indicates that $\Delta H$ is independent of temperature for each case (see Edsall and Gutfreund 1983). At 3-5 $L_{0} / \mathrm{s}$, a shortening velocity producing the maximum power at the physiological temperatures, $T_{0.5}$ is $\sim 28^{\circ} \mathrm{C}$ (Figs. 3, 4) and $\Delta H$ is $\sim 200 \mathrm{~kJ} \mathrm{~mol}^{-1}$, approximately twice that of isometric; $T \Delta S$ at $35^{\circ} \mathrm{C}$ was $\sim 210 \mathrm{~kJ} \mathrm{~mol}^{-1}$. Thus, since $\Delta \mathrm{G}$ (free energy change) $=\Delta H-T \Delta S$, it seems that the temperature $T_{0.5}$ for the minimum $\Delta \mathrm{G}$ is increased in shortening muscle. The enthalpy changes of various molecular steps in the myosin ATPase reaction in solution also have been calorimetrically determined (see Kodama and Woledge 1979; Kodama 1985; Millar et al. 1987) and, to some extent, they can be correlated with the crossbridge cycle in isometric muscle (see Zhao and Kawai 1994; Coupland et al. 2001); such experiments indicate that the summed $\Delta \mathrm{H}$ for the molecular steps Pi-release, ADP-release, ATP-binding and ATP-hydrolysis is $-18 \mathrm{~kJ} \mathrm{~mol}^{-1}$ so that, in the actomyosin cycle in muscle, the net endothermic process may be the force generation step before Pi-release in isometric muscle.

In general terms, the results show that the "endothermic character" is enhanced, in a velocity dependent manner, in the shortening muscle; the findings are consistent with the well known principle regarding the energetics of a muscle's physiological performance, "the Fenn effect", that energy liberation is increased in shortening muscle doing external work (Fenn 1924).

(3) At a given ramp velocity, the observed rate of tension decline during shortening had low temperature-sensitivity in both intact and skinned fibres $\left(Q_{10} \mathrm{~s}<1.5\right.$, Figs. 6,8$)$; this contrasts with high temperature sensitivity obtained in our previous studies for many other contraction parameters of mammalian muscle (Ranatunga 1982; Ranatunga and Wylie 1983). In terms of a crossbridge cycle, the tension decline during ramp shortening involves a combination of two processes, force loss due to detachment of originally attached force generating crossbridges and force generation by newly attached crossbridges (Roots et al. 2007). Since crossbridge force generation is an endothermic process (Bershitsky and Tsaturyan 1992; Davis and Harrington 1987; Goldman et al. 1987) with a high $Q_{10}$ (Zhao and Kawai 1994; Ranatunga 1996), which is also evident with $T$-jumps in the present experiments (see Figs. 7, 8), the results suggest that crossbridge detachment process that drives the tension decline during ramp shortening may 

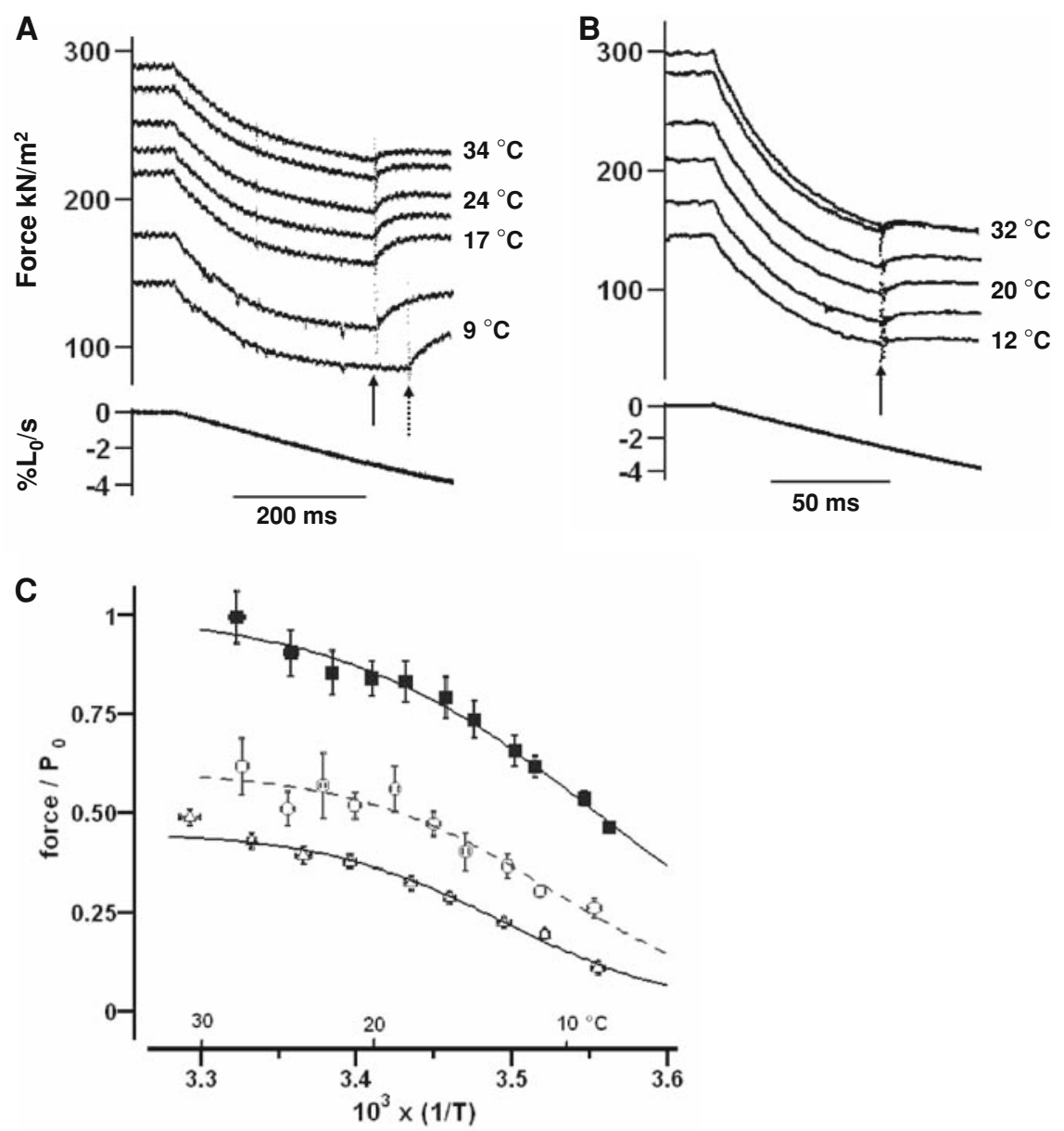

Fig. 7 Experimental data from skinned (rabbit psoas) fibres. A fibre held isometric was maximally $\mathrm{Ca}$-activated at low temperature $\left(<9^{\circ} \mathrm{C}\right)$ and, at isometric tension plateau, a ramp shortening (lower trace) applied; during steady shortening, a standard $T$-jump $\left(3-4^{\circ} \mathrm{C}\right)$ was induced by a laser pulse (arrow). The procedure was repeated after the trough temperature was rapidly increased and clamped (by the Peltier system) at different temperatures. From each record the pre-shortening isometric force and the pre and post- $T$-jump shortening forces were determined. Experimental traces are from 2 fibres; (a) shortening velocity of $0.05 L_{0} / \mathrm{s}$ with $\sim 3^{\circ} \mathrm{C} T$-jumps and (b) velocity of $0.5 L_{0} / \mathrm{s}$ with $\sim 4^{\circ} \mathrm{C} T$-jumps. The temperature after a $T$-jump is given for alternate tension traces. (c) Mean ( \pm s.e.m., $n=4-8$ per point) force data from 7 fibres are plotted against reciprocal absolute

indeed be temperature-insensitive, or has a "negative" temperature sensitivity. Some effects of series compliance and sarcomere non-uniformity etc in our experiments can not of course be excluded, even though the tendon length was kept short in our preparations (see "Methods"); on the other hand, it may be argued that, series compliance would decrease the actual rate but not necessarily its temperaturesensitivity. Although our measurements relate to shortening muscle, the observations are consistent with the findings of Zhao and Kawai (1994) who found low temperature sensitivity $\left(Q_{10} \sim 1.1\right)$ for the rate-limiting step of the crossbridge cycle in isometric muscle $\left(k_{6}\right.$ in their model). temperature. Isometric force data (filled squares) are from all the fibres; force data during shortening at a low velocity range (0.05-0.09 $L_{0} / \mathrm{s}$, open circles) are from 4 of the fibres and those at a higher velocity range $\left(0.5-0.9 L_{0} / \mathrm{s}\right.$, open triangles) are from 3 fibres. A sigmoidal curve (see "Methods") is fitted to each pool of original data $(P<0.001) ; P_{\max }$ (as a ratio of $P_{0}$ at $\sim 30^{\circ} \mathrm{C}$ ), $\Delta H\left(\right.$ in $^{\mathrm{kJ} \mathrm{mol}}{ }^{-1}$ ) and $T_{0.5}$ (in ${ }^{\circ} \mathrm{C}$ ) were $1.0,100$ and 8.4 for the isometric, $0.61,130$ and 11 for the low velocity and $0.45,142$ and 13 for the higher velocity data; $\Delta S$ values $\left(\mathrm{Jmol}^{-1} \mathrm{~K}^{-1}\right)$ were 356,457 and 496 , respectively for the isometric, low- and high-velocity cases. Similar data were obtained from vant Hoff plots, as found in intact fibre experiments (Figs. 3, 4). $P_{0}$ at $8-10^{\circ} \mathrm{C}$ was $169 \pm 16 \mathrm{kN} \mathrm{m}^{-2}(n=7)$ so that $P_{\max }$ would be $338 \mathrm{kN} \mathrm{m}^{-2}$ (at $>30^{\circ} \mathrm{C}$ )

The sigmoidal temperature dependence of muscle force and a simulation

From several different studies of muscle proteins in solution, considerable body of knowledge is available on the thermodynamics of the myosin- and acto-myosin ATPase mechanisms. With respect to temperature-dependence, such studies have shown the need to identify two fundamental conformations of myosin, one (referred to in different studies as $\mathrm{M}_{\mathrm{L}}$ - or $R$-state) favoured by low temperature and the other $\left(\mathrm{M}_{\mathrm{H}^{-}}\right.$or $T$-state $)$ favoured by high temperature. Moreover, the relative populations of the two 


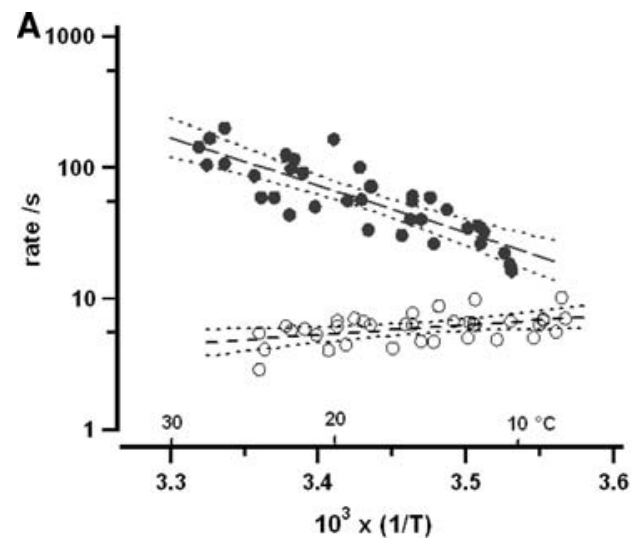

Fig. 8 Rates of tension decline and $T$-jump tension rise during steady shortening. Pooled kinetic data from skinned fibre experiments for the rate of tension decline during ramp shortening (open symbols) and for the rate of tension rise induced by a $T$-jump (filled symbols). Data were obtained by exponential curve fit to appropriate parts of the tension traces (as in Fig. 7a, b) and they are presented as Arrhenius plots; lines through the points are the fitted regressions with $95 \%$ confident limits. (a) Data at the low velocity range $\left(0.05-0.09 L_{0} / \mathrm{s}\right)$ from 4 fibres $(n=34) ; Q_{10}$ for rate of tension decline is 0.85 and $Q_{10}$

states would not only be determined by temperature but also the nucleotide on the myosin binding site (see reviews Kodama 1985; Shriver 1984). Given that isometric tension, either in relaxed muscle fibres (i.e. stretched passive tension and no crossbridges attached) or in rigor fibres (no ATP; crossbridges attached), does not show a sigmoidal relation (see Ranatunga 1994), the sigmoidal temperature dependence of muscle force is associated with actively cycling of crossbridges. If the two acto-myosin conformations above can be linked with force generation mechanisms in muscle, in broad outline, the sigmoidal temperature dependence of active muscle force and its sensitivity Pi and ADP (see "Introduction") would be explicable.

In an attempt to simulate the basic trends seen in our experimental data, we used a minimal three-step actomyosin ATPase/crossbridge cycle (see Scheme 1 in "Methods") that qualitatively modelled the effects of increased $\mathrm{Pi}$ on the force versus temperature relation in isometric muscle (Coupland et al. 2001). Basically, the scheme contains a reversible endothermic force generation (step 1) coupled to reversible Pi-release (step 2) and an irreversible step (step 3) completing the cycle; the temperature-sensitivity of force was due to increase of forward rate constant in step 1 and the isometric force was calculated as the sum of occupancy of states 2 and 3. Figure 9a shows the tensions calculated for different temperatures in control (filled squares, assumed to contain $0.5 \mathrm{mM} \mathrm{Pi}$ ) and with increased $\mathrm{Pi}$ (to $1 \mathrm{mM}$ and $25 \mathrm{mM}$-open circles) and each data set is fitted with a sigmoidal curve; as found in experiments (Coupland et al. 2001), the curve is shifted to

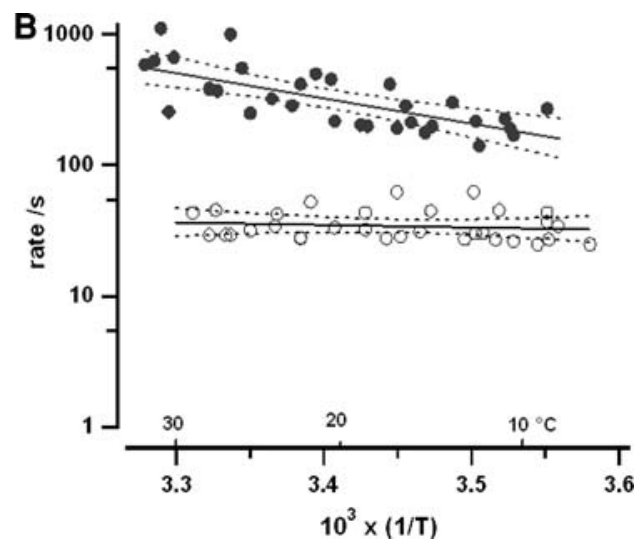

for $T$-jump tension rise is 2.6. (b) Data at the higher velocity range $\left(0.5-0.9 L_{0} / \mathrm{s}\right)$ from 3 fibres $(n=32) ; Q_{10}$ for tension decline is $\sim 1$ and for $T$-jump tension rise is 1.7. Note that the apparent rate of tension decline during ramp shortening is not very temperature sensitive as found in intact fibres (Fig. 6), but $T$-jump tension data indicate existence of a temperature-sensitive (endothermic) component; also, both rates are lower for low velocity (A) than for higher velocity (B) of shortening but their temperature sensitivities are different

higher temperatures with increased Pi. Figure $9 \mathrm{~b}$ shows that similar shifts of the curve, showing increase of $T_{0.5}$, are obtained by increasing the rate constant of the irreversible step (decreasing this would shift the curve to lower temperature - as found experimentally with increased MgADP, Coupland et al. 2005). In either case, however, the $\Delta H$ and $\Delta S$ were not much altered by such changes in the rate constants of the kinetic scheme (see Fig. 9 for details).

In order to obtain, the temperature dependent behaviour of shortening muscle force-when the irreversible step is made faster, the occupancy data that represent force needed to be transformed, based on two established principles on the mechanics of crossbridge cycle (see "Methods" for details). Firstly, since at a certain critical low temperature $\left(T_{\mathrm{c}}\right)$, a given velocity would represent the $\mathrm{V}_{\max }$, where force is zero, the occupancy at $T_{\mathrm{c}}$ was subtracted from $\operatorname{Occ}(2+3)$ for that velocity at all the temperatures. Secondly, the average positive force exerted by a crossbridge would be less during shortening, being exposed to negative strain. Figure 10a shows the data transformed in this manner for a number of shortening velocities (taken as 0.2 to $4-5 L_{0} / \mathrm{s}$-see "Methods"), Fig. 10b shows vant Hoff's plots and Fig. 10c shows the force-velocity curves for three temperatures. The data from this simulation do illustrate the basic features of the experimental findings, particularly, the increase with shortening velocity of $T_{0.5}$, $\Delta H$ and $\Delta S$ (see Fig. 11); also, the simulated force-velocity curves (Fig. 10c) show qualitatively the basic characteristics seen in the experimental force-velocity curves (Fig. 2a), namely, increased $\mathrm{V}_{\max }$ and decreased curvature at the higher temperature. 


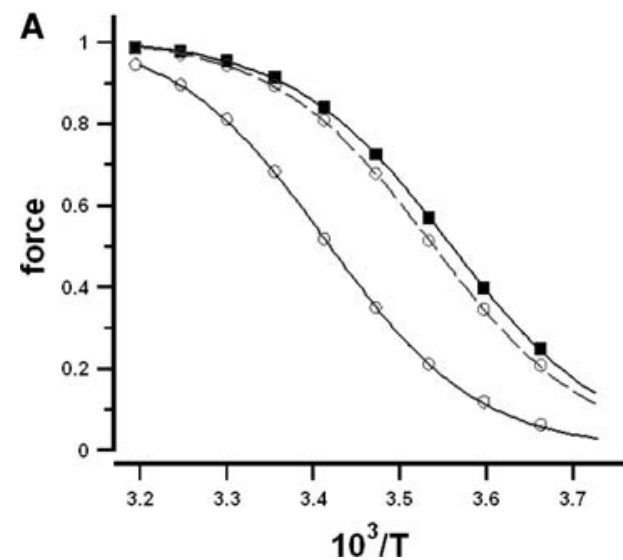

Fig. 9 Model simulations of steady force at different temperatures. Using a three state crossbridge cycle, and taking the summed occupancy of [AM*.ADP.Pi] and [AM*ADP] as (isometric) tension, tensions were calculated at $5^{\circ} \mathrm{C}$ intervals between 0 and $40^{\circ} \mathrm{C}$; temperature effect was simulated by increasing $k_{\mathrm{a}}$ with a $Q_{10}$ of 4 (see "Methods" for details). The calculated tensions (symbols) are plotted against reciprocal absolute temperature and a sigmoidal curve is fitted to each data; for clarity symbols for some curves are not displayed. (a) Filled squares were calculated with $0.5 \mathrm{mM}$ Pi (taken as control) and open circles and dashed curve with $1 \mathrm{mM}$ Pi and continuous curve with $25 \mathrm{mM} \mathrm{Pi}$; increase of Pi was simulated by setting $k_{\mathrm{d}}$. The sigmoidal curve is shifted to higher temperatures with increased $\mathrm{Pi}$; $\Delta H$ from the curve fits increased slightly, $90-94 \mathrm{~kJ} \mathrm{~mol}^{-1}$, and $\Delta S$ (as

Some features and assumptions in the model

A few of the features and assumptions intrinsic to the minimal three-step cycle that qualitatively simulated the basic trends in the experimental data are worthy of note (see also "Methods").

(1) The model assumed that, except for the (single) force generation step (endothermic, $k_{\mathrm{a}}$ in step I), all other (forward and backward) steps in the cycle as insensitive to temperature; indeed, the tension decline during ramp shortening (crossbridge detachment) was found to have a low temperature-sensitivity (see above).

(2) An increase of $k_{\mathrm{e}}$, (rate of irreversible step) to simulate crossbridge operation in shortening muscle (higher cycling rate, Huxley 1957) resulted in a shift of the sigmoidal curve to higher temperatures (an increase of $T_{0.5}$ ) as in the experiments, but it failed to simulate the marked increase of $\Delta H$ and $\Delta S$ in the experiments. The two further transformations that had to be done, in principle, amount to a decrease of the number of attached crossbridges and their contribution to force in shortening muscle (see Methods). From X-ray interference and mechanical measurements, Piazzesi et al. (2007) concluded that the force-shortening velocity relation of muscle is primarily a result of a reduction in the number of attached crossbridges, rather than the crossbridge force or stroke size; in our modelling, however, a decrease with shortening velocity of the average force per crossbridge was necessary to account for our

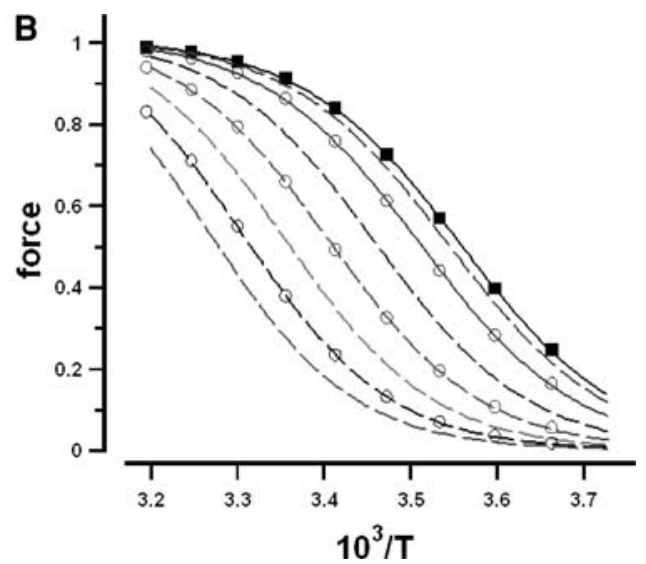

$\left.\Delta H / T_{0.5}\right)$ is $\sim 320 \mathrm{~J} \mathrm{~mol}^{-1} \mathrm{~K}^{-1}$, unchanged, more or less as obtained in the experiments, previously (Coupland et al. 2001). (b) Effect of increasing $k_{\mathrm{e}}$ (to simulate shortening) on tension at [Pi] of $0.5 \mathrm{mM}$ (control). Filled squares represent the control with $k_{\mathrm{e}(\mathrm{isom})}=10 / \mathrm{s}$ and curves from right to left are when $k_{\mathrm{e}}$ was increased to values ranging from $12.5 / \mathrm{s}$ to $640 / \mathrm{s}$; taking shortening velocity $(\mathrm{V})=\log _{\mathrm{e}}\left(k_{\mathrm{e}} /\right.$ $k_{\text {e(isom) }}$ ), the shortening velocity range is $0.2-4 L_{0} / \mathrm{s}$. Note that the curves shift to higher temperatures as $\mathrm{V}$ is increased; $\Delta H$ from the curve fits increased modestly, $90-97 \mathrm{~kJ} \mathrm{~mol}^{-1}$ and $\Delta S$ was $\sim 320$ $\mathrm{J} \mathrm{mol}^{-1} \mathrm{~K}^{-1}$, between isometric and highest V. Thus, increase of $k_{\mathrm{e}}$ alone does not simulate adequately the temperature dependence of steady force (marked increase of $\Delta H$ and $\Delta S$ ) in shortening muscle

findings, as generally considered (see "Methods"; Huxley et al. 2006) and also suggested from other recent studies in literature (e.g. Bagni et al. 2005).

(3) The temperature-dependent increase of force in isometric case is attributed conversion of low-force to high-force attached states with little change in the total number of attachments (see above). In the model, the number of attached crossbridges during shortening was lower than in isometric (see above), but remained unchanged at the different temperatures, so that the increase of force was still due to conversion of low-force to high-force attached states. This seems a remarkable simplification that requires experimental scrutiny in the future. Exactly why the number of attached crossbridges in maximally activated muscle is not much altered by temperature changes, even in isometric muscle (Fig. 2a), remains unclear; a more complex mechano-kinetic model, incorporating strain-sensitivity to the force generation step, would be required to achieve accurate simulation of both the steady state data and the tension transients.

Endothermic nature of muscle force generation

Following the original experiments and formulations by Huxley and Simmons (1971), quick tension recovery induced by a small length-release step is thought to represent crossbridge power stroke or force generation in muscle; Gilbert and Ford (1988) showed experimentally 


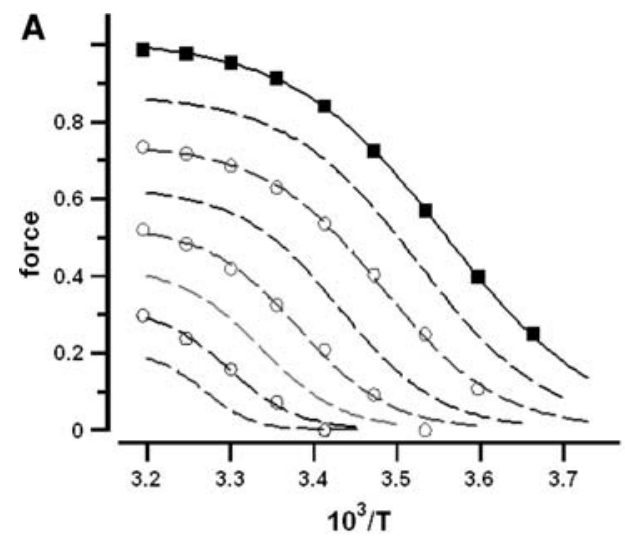

C

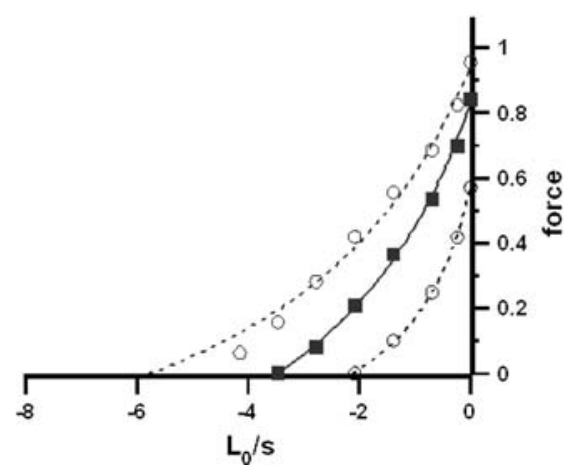

Fig. 10 Simulations of steady force during shortening. The occupancy of $\left[\mathrm{AM}^{*} \mathrm{ADPPi}+\mathrm{AM}^{*} \mathrm{ADP}\right]$, i.e. force-holding attached crossbridges, was transformed on the basis of two established principles. (1) Compared to isometric, the average force per crossbridge would be less during shortening at $\mathrm{V}$, due to negative strain on them. (2) Depending on $\mathrm{V}$, the force will be zero at a certain low temperature $\left(T_{\mathrm{c}}\right)$ at which the number of crossbridges with negative strain $=$ the number with positive strain; hence, the occupancy at $T_{\mathrm{c}}$ (e.g. $\sim 10^{\circ} \mathrm{C}$ for $\mathrm{V}$ of $\sim 2 L_{0} / \mathrm{s}$ ) was subtracted from the occupancy at all other temperatures. Thus, occupancy data (Occ) at different temperatures for a given $\mathrm{V}$ were transformed as, Force $($ short $)=\left[\mathrm{Occ}_{(\text {isom })}-\operatorname{Occ}\left(T_{\mathrm{c}}\right)\right] \times \mathrm{r}$, where $\mathrm{r}$ decreased from 1 for isometric to 0.4 for $\sim 4 L_{0} / \mathrm{s}$; since $T_{\mathrm{c}}$ was known for some

that there is heat absorption during quick tension recovery and concluded that force generation would be entropy driven. Also, a rapid $T$-jump increases isometric force without appreciable delay showing that force rises on absorption of heat (endothermic - see "Introduction"). Additionally, exposure to high hydrostatic pressure reduces force in isometric muscle fibres and force quickly recovers on rapid pressure release; thus, force generation at constant temperature may be accompanied by a volume increase (Fortune et al. 1991; Vawda et al. 1999). Therefore, the endothermic nature of muscle (crossbridge) force generation, and increase of entropy associated with it, have been well recognised from studies on isometric muscle and the present study shows that these features are enhanced in shortening muscle performing external work.

A conformational change of the acto-myosin crossbridge, resulting in lever arm tilting, is thought to be the

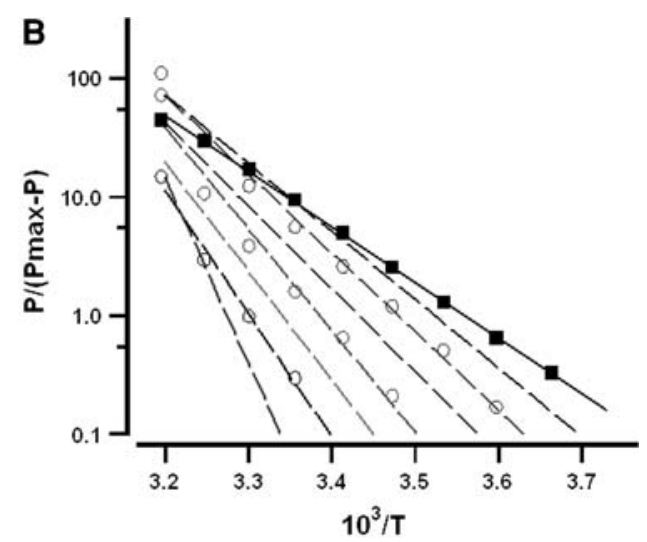

velocities from experiment, $\operatorname{Occ}\left(T_{\mathrm{c}}\right)$ could be easily obtained from the model but for others, it was estimated (see "Methods" for details). (a) Filled squares are isometric force data and others are transformed occupancy data representing force during shortening at different velocities (range $0.2-4 L_{0} / \mathrm{s}$ ); a sigmoidal curve is fitted to each data set as in Fig. 8. (b) vant Hoff's plot of the data; note the increase of slope $(\Delta H)$ and increase of intercept at $1 / T$ of zero $(\Delta S)$ with increase of velocity (from right to left), as found in the experimental data. (c) Force-velocity curves for $\sim 10, \sim 20$ and $\sim 30^{\circ} \mathrm{C}$ from the above simulations; although the data transformation was not exact, an increase of $\mathrm{V}_{\max }$ and a decrease of curvature are seen with warming, as in the experiments (see Fig. 3)

molecular-structural mechanism of force muscle generation (see review Geeves and Holmes 1999); how this is associated with increased entropy (disorder) remains unclear. Two different molecular-structural mechanisms have been proposed to account for the increase of entropy during force generation by an acto-myosin crossbridge. Firstly, Zhao and Kawai (1994) suggested and favoured a mechanism involving altered hydrophobic interaction between actin and myosin (S1) for the large increase of entropy (see also, Kodama 1985); in principle, the transition of non-stereo-specifically attached to stereospecifically attached crossbridge states would represent such an event, since stereospecific interaction may be hydrophobic. From examination of X-ray diffraction pattern of muscle fibres during force rise induced by rapid $T$ jumps, Bershitsky et al. (1997) proposed such a mechanism as a force generating step that is additional to the lever arm 


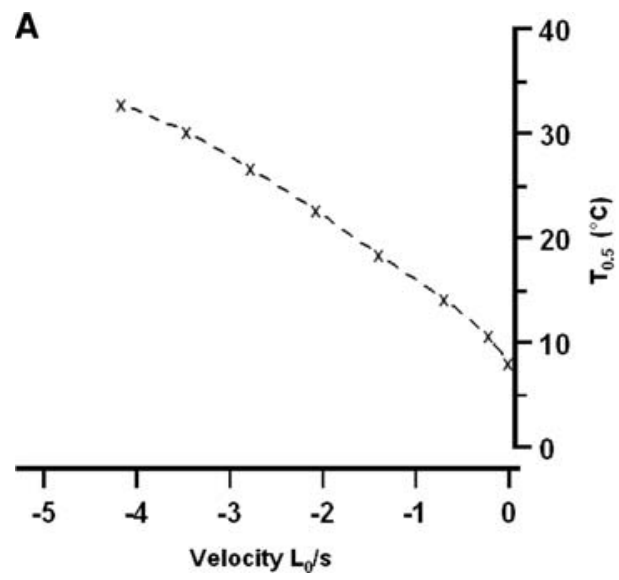

Fig. 11 Thermodynamic parameters extracted from simulated tension data. A summary illustration of the indices extracted from the analyses, shown in Fig. 10, from simulations; data presentation is similar to Fig. 5. (a) The temperature for half-maximal tension, $T_{0.5}$ in ${ }^{\circ} \mathrm{C}$, increases with increase of shortening velocity. (b) $\Delta H$ (in kJ mol${ }^{-}$ ${ }^{1}$ ) - lower data set and $\Delta S$ (in $\mathrm{J} \mathrm{mol}^{-1} \mathrm{~K}^{-1}$ ) —upper data set-are

tilting step in the crossbridge cycle (see Ferenczi et al. 2005). A contribution of such a mechanism to an entropy increase can not be excluded, although whether it is intrinsic to crossbridge force generation alone remains to be established.

Secondly, Davis and Epstein (2007) proposed an alternative mechanism, namely, a local unfolding within the crossbridge secondary/tertiary structure and suggested that this might cause the lever arm tilting movement and force generation. From analyses of the rate of tension rise induced by $T$-jumps at different temperatures as Arrhenius plots, they showed that the observed rate could be resolved into the forward and reverse rate constants for force generation $\left(k_{\mathrm{a}} / k_{\mathrm{b}}\right.$ of step-I in our Scheme) with clearly different temperature-sensitivities; in particular, the reverse rate constant showed anti-Arrhenius behaviour (negative temperature-sensitivity) characteristic for protein folding. Our results show that the increase of entropy becomes even larger in shortening muscle, i.e. when the attached crossbridges are exposed to continuous negative strain by filament sliding, the number of attachments is reduced and the crossbridge cycle is operating faster. Arrhenius plots for the observed rate of $T$-jump-induced tension rise, during shortening at two velocities (Fig. 8a, b filled symbols), show no obvious evidence of a non-linearity as expected; however, this might be due to scatter in the pooled data. Also, our findings suggest that another step in the cycle may also have negative temperature-sensitivity, although this is not shown conclusively.

As stated by Gilbert and Ford (1988), since the energy transduction by the actomyosin ATPase in muscle is a cyclic process, an increase in the entropy of the system in one part of the cycle requires a decrease in entropy in

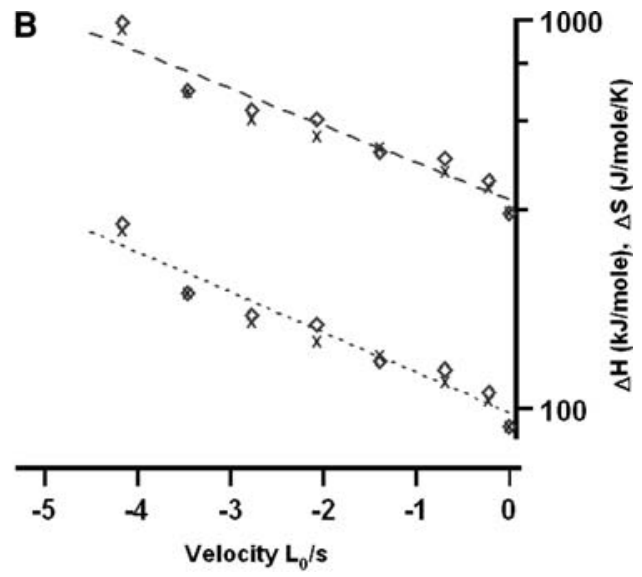

plotted on logarithmic ordinates. Note that, basically as in the two different types of experiments in Fig. 5, both $\Delta H$ and $\Delta S$ from simulated tensions increase similarly with increase of shortening velocity; values from sigmoidal curve fit and from vant Hoff's plots (different symbols) are shown

another part. It is possible that, whereas the entropy increase is associated with force generation, the entropy decrease may not be restricted to a single step in the cycle, at least in shortening muscle performing external work; further experiments to gather data amenable to more quantitative and detailed analyses would be required to resolve these uncertainties.

Acknowledgements We thank The Wellcome Trust for the support of our research, Dr Gerald Offer (University of Bristol) and Professor Mike Geeves (University of Canterbury) for discussions and interest in the work and Professor Giovanni Cecchi (University of Florence) for comments on the manuscript.

Open Access This article is distributed under the terms of the Creative Commons Attribution Noncommercial License which permits any noncommercial use, distribution, and reproduction in any medium, provided the original author(s) and source are credited.

\section{References}

Bagni AM, Cecchi G, Colombini B (2005) Crossbridge properties investigated by fast ramp stretching of activated frog muscle fibres. J Physiol 565:261-268

Bershitsky SY, Tsaturyan AK (1990) Tension transients initiated by the Joule temperature jump during steady shortening of skinned muscle fibres. In: Maréchal G, Carraro U (eds) Muscle \& motility. Intercept, Andover, Hampshire, pp 277-281

Bershitsky SY, Tsaturyan AK (1992) Tension responses to Joule temperature jump in skinned rabbit muscle fibres. J Physiol 447:425-448

Bershitsky SY, Tsaturyan AK, Bershitskaya ON, Mashanov GI, Brown P, Burns R, Ferenczi MA (1997) Muscle force is generated by myosin heads stereospecifically attached to actin. Nature 388:186-189

Brown DES (1957) Temperature-pressure relation in muscular contraction. In: Johnson FH (ed) Influence of temperature on biological systems. Am Physiol Soc Inc., pp 83-100 
Coupland ME, Ranatunga KW (2003) Force generation induced by rapid temperature jumps in intact mammalian (rat) skeletal muscle fibres. J Physiol 548:439-449

Coupland ME, Puchert E, Ranatunga KW (2001) Temperature dependence of active tension in mammalian (rabbit psoas) muscle fibres; effect of inorganic phosphate. J Physiol 536:879-891

Coupland ME, Pinniger GJ, Ranatunga KW (2005) Endothermic force generation, temperature-jump experiments and effects of increased $[\mathrm{MgADP}]$ in rabbit psoas muscle fibres. J Physiol 567:471-492

Dantzig JA, Goldman YE, Millar NC, Lacktis J, Homsher E (1992) Reversal of the cross-bridge force-generating transition by photogeneration of phosphate in rabbit psoas muscle fibres. $\mathbf{J}$ Physiol 451:247-278

Davis JS (1998) Force generation simplified. Insights from laser temperature-jump experiments on contracting muscle fibers. Adv Exp Med Biol 453:343-351

Davis JS, Epstein ND (2007) Mechanism of tension generation in muscle: an analysis of the forward and reverse rate constants. Biophys J 92:2865-2874

Davis JS, Harrington WF (1987) Force generation in muscle fibers in rigor: a temperature-jump study. Proc Natl Acad Sci USA 84:975-979

Edsall JT, Gutfreund H (1983) Bio-thermodynamics. Wiley, Chichester

Elmubarak MH, Ranatunga KW (1984) Temperature sensitivity of tension development in a fast-twitch muscle of the rat. Muscle Nerve 7:298-303

Fenn WO (1924) The relationship between the work performed and the energy liberated in muscular contraction. J Physiol 59:373395

Ferenczi MA, Bershitsky SY, Koubassova N, Siththanadan V, Helsby WI, Pannine P, Roessle M, Narayan T, Tsaturyan AK (2005) The "Roll and Lock" mechanism of force generation in muscle. Structure 13:131-141

Ford LE, Huxley AF, Simmons RM (1977) Tension responses to sudden length change in stimulated frog muscle fibres near slack length. J Physiol 269:441-515

Ford LE, Huxley AF, Simmons RM (1985) Tension transients during steady shortening of frog muscle fibres. J Physiol 361:131-150

Fortune NS, Geeves MA, Ranatunga KW (1991) Tension responses to rapid pressure release in glycerinated rabbit muscle fibers. Proc Natl Acad Sci USA 88:7323-7327

Geeves MA, Holmes KC (1999) Structural mechanism of muscle contraction. Ann Rev Biochem 68:687-728

Gilbert SH, Ford LE (1988) Heat changes during transient tension responses to small releases in active frog muscle. Biophys $\mathbf{J}$ 54:611-677

Goldman YE, McCray JA, Ranatunga KW (1987) Transient tension changes initiated by laser temperature jumps in rabbit psoas muscle fibres. J Physiol 392:71-95

Hadju S (1951) Behaviour of frog and rat muscle at higher temperatures. Enzymologia 14:187-190

He Z-H, Bottinelli R, Pellegrino MA, Ferenczi MA, Reggiani C (2000) ATP consumption and efficiency of human single muscle fibers with different myosin isoform composition. Biophys $\mathrm{J}$ 79:945-961

Hill AV (1938) The heat of shortening and the dynamic constants of muscle. Proc R Soc Lond B 126:136-195

Huxley AF (1957) Muscle structure and theories of contraction. Prog Biophys 7:285-318

Huxley AF, Simmons RM (1971) Proposed mechanism of force generation in striated muscle. Nature 233:533-538

Huxley H, Reconditi M, Stewart A, Irving T (2006) X-ray interference studies of crossbridge action in muscle contraction: evidence from muscles during steady shortening. J Mol Biol 363:762-772
Julian FJ, Morgan DL (1981) Variation of muscle stiffness with tension during tension transients and constant velocity shortening in the frog. J Physiol 319:193-203

Kawai M, Halvorson HR (1991) Two step mechanism of phosphate release and the mechanism of force generation in chemically skinned fibers of rabbit psoas muscle. Biophys J 59:329-342

Kawai M, Kido T, Vogel M, Fink RHA, Ishiwata S (2006) Temperature change does not affect force between regulated actin filaments and heavy meromyosin in single molecule experiments. J Physiol 574:877-878

Kodama T (1985) Thermodynamic analysis of muscle ATPase mechanisms. Physiol Rev 65:467-551

Kodama T, Woledge RC (1979) Enthalpy changes for intermediate steps of the ATP hydrolysis catalyzed by myosin subfragment- 1 . J Biol Chem 254:6382-6386

Millar NC, Howarth JV, Gutfreund H (1987) A transient kinetic study of enthalpy changes during the reaction of myosin subfragment 1 with ATP. Biochem J 248:683-690

Mutungi G, Ranatunga KW (2001) The effects of ramp stretches on active contractions in intact mammalian fast and slow muscle fibres. J Muscle Res Cell Motil 22:175-184

Piazzesi G, Reconditi M, Linari M, Lucii L, Bianco P, Brunello E, Decostre V, Stewart A, Gore DB, Irving TC, Irving M, Lombardi V (2007) Skeletal muscle performance determined by modulation of number of myosin motors rather then motor force or stroke size. Cell 131:784-795

Ranatunga KW (1982) Temperature dependence of shortening velocity and rate of isometric tension development in rat skeletal muscle. J Physiol 329:465-483

Ranatunga KW (1984) The force-velocity relation of rat fast- and slow-twitch muscles examined at different temperatures. J Physiol 351:517-529

Ranatunga KW (1994) Thermal stress and Ca-independent contractile activation in mammalian skeletal muscle fibers at high temperatures. Biophys J 66:1531-1541

Ranatunga KW (1996) Endothermic force generation in fast and slow mammalian (rabbit) muscle fibers. Biophys J 71:1905-1913

Ranatunga KW (1998) Temperature dependence of mechanical power output in mammalian (rat) skeletal muscle. Exp Physiol 83:371376

Ranatunga KW (1999) Effects of inorganic phosphate on endothermic force generation in muscle. Proc R Soc Lond B 266:13811385

Ranatunga KW, Wylie SR (1983) Temperature dependent transitions in isometric contractions of rat muscle. J Physiol 339:87-95

Ranatunga KW, Coupland ME, Pinniger GJ, Roots H, Offer GW (2007) Force generation examined by laser temperature-jumps in shortening and lengthening mammalian (rabbit psoas) muscle fibres. J Physiol 585:263-277

Roots HR, Offer GW, Ranatunga KW (2007) Comparison of the tension response to ramp shortening and lengthening in intact mammalian muscle fibres: crossbridge and non-crossbridge contributions. J Muscle Res Cell Motil 28:123-139

Shriver JW (1984) Energy transduction in myosin. TIBS 9:322-328

Sleep J, Irving M, Burton K (2005) The ATP hydrolysis \& phosphate release steps control time course of force development in rabbit skeletal muscle. J Physiol 563:671-687

ter Keurs HE, Luff AR, Luff SE (1984) Force-sarcomere-length relation and filament length in rat extensor digitorum muscle. Adv Exp Med Biol 170:511-525

Vawda F, Geeves MA, Ranatunga KW (1999) Force generation upon hydrostatic pressure release in tetanized frog muscle fibres. J Muscle Res Cell Motil 20:477-488

Zhao Y, Kawai M (1994) Kinetic and thermodynamic studies of the crossbridge cycle in rabbit psoas muscle fibers. Biophys $\mathrm{J}$ 67:1655-1668 